\title{
Synthesis of a High-Temperature Stable Electrochemically Exfoliated Graphene
}

DOI:

10.1016/j.carbon.2019.10.042

\section{Document Version}

Accepted author manuscript

Link to publication record in Manchester Research Explorer

\section{Citation for published version (APA):}

Sharif, F., Zeraati, A. S., Ganjeh-Anzabi, P., Yasri, N., Perez-Page, M., Holmes, S., Sundararaj, U., Trifkovic, M., \& Roberts, E. P. L. (2019). Synthesis of a High-Temperature Stable Electrochemically Exfoliated Graphene. Carbon, 157, 681-692. https://doi.org/10.1016/j.carbon.2019.10.042

\section{Published in:}

Carbon

\section{Citing this paper}

Please note that where the full-text provided on Manchester Research Explorer is the Author Accepted Manuscript or Proof version this may differ from the final Published version. If citing, it is advised that you check and use the publisher's definitive version.

\section{General rights}

Copyright and moral rights for the publications made accessible in the Research Explorer are retained by the authors and/or other copyright owners and it is a condition of accessing publications that users recognise and abide by the legal requirements associated with these rights.

\section{Takedown policy}

If you believe that this document breaches copyright please refer to the University of Manchester's Takedown Procedures [http://man.ac.uk/04Y6Bo] or contact uml.scholarlycommunications@manchester.ac.uk providing relevant details, so we can investigate your claim.

\section{OPEN ACCESS}




\title{
Synthesis of a High-Temperature Stable Electrochemically Exfoliated Graphene
}

\author{
Farbod Sharif ${ }^{1}$, Ali Shayesteh Zeraati ${ }^{1}$, Pejman Ganjeh-Anzabi ${ }^{1}$, Nael Yasri ${ }^{1}$, Maria Perez- \\ Page $^{2}$, Stuart M. Holmes ${ }^{2}$, Uttandaraman Sundararaj ${ }^{1}$, Milana Trifkovic ${ }^{1}$, Edward P. L. Roberts ${ }^{1 *}$ \\ ${ }^{1}$ University of Calgary, Department of Chemical and Petroleum Engineering, 2500 \\ University Drive NW, Calgary, AB T2N 1N4, Canada \\ ${ }^{2}$ School of Chemical Engineering and Analytical Science, University of Manchester, \\ Manchester M13 9PL, UK
}

\begin{abstract}
A new and facile electrochemical exfoliation approach is proposed to produce better quality electrochemically exoliated graphene with exellent high-temperature stability. The method is based on graphene exfoliation in inorganic electrolytes (e.g. $\left(\mathrm{NH}_{4}\right)_{2} \mathrm{HPO}_{4}$ and $\left(\mathrm{NH}_{4}\right)_{2} \mathrm{SO}_{4}$ and different combinations of these salts) where the electrolyte composition was found to have a significant impact on the yield, morphology, structure, and high-temperature stability of the graphene sheets. The graphene prepared using $\left(\mathrm{NH}_{4}\right)_{2} \mathrm{HPO}_{4}$ electrolyte showed the lowest level of defects in comparison to the other electrochemically exfoliated graphene and an exceptional hightemperature stability in air, at temperatures of up to $750{ }^{\circ} \mathrm{C}$; much higher than typical high surface area carbon materials which are unstable around $400{ }^{\circ} \mathrm{C}$ to $500{ }^{\circ} \mathrm{C}$ in air. The addition of $\left(\mathrm{NH}_{4}\right)_{2} \mathrm{SO}_{4}$ to the $\left(\mathrm{NH}_{4}\right)_{2} \mathrm{HPO}_{4}$ electrolyte improved the exfolation process and increased the production of single layer graphene sheets from $19 \%$ to $\sim 50 \%$. These hybrid electrolytes also led
\end{abstract}

*Corresponding Author. Tel: 403 220-4466.

Email: edward.roberts@ucalgary.ca (Edward Roberts) 
to nitrogen, phosphorus, and sulphur tri-doped graphene sheets with a fewer defects and hightemperature stability in air. This simple process offers a promising approach for large scale preparation of doped graphene with fewer defects and exceptional properties for various applications.

\section{Introduction}

Graphene with its 2-dimensional structure has attracted a great amount of attention in electrochemistry due to its exceptional properties, such as its large aspect ratio, high surface area, superior conductivity and catalytic activity [1]. Therefore, there has been a great amount of effort to tune graphene properties for specific applications. Well-developed graphene-based materials with tunable surface chemistry have shown promising results as catalysts [2] or catalyst supports $[3,4]$. The world demand for graphene is increasing due to its potential in catalysis as well as other applications namely adsorption [5,6], fuel cells [7], sensors [8], and batteries [9]. Graphene can be synthesized through different methods such as mechanical exfoliation of graphite [10], chemical vapor deposition (CVD) [11], or reduction of graphene oxide [12]. However, obtaining high quality graphene sheets with a simple approach is still challenging. Recently, graphene obtained by the electrochemical exfoliation of graphite has received considerable attention as it offers a simple, environmentally friendly and scalable process that is capable of producing good quality graphene [13]. Electrochemically exfoliated graphene has been synthesized in different types of electrolytes such as ionic liquids [14,15], acidic media [16,17], and inorganic salts [18,19]. Among these, inorganic salts has been found to produce graphene with large lateral size and lower amount of oxygen functional groups compared to other types of electrolytes [20]. 
There is a correlation between the quality of graphene and the utilized electrolyte. Once exfoliation occurs under anodic conditions, a potential bias has to be applied to facilitate the intercalation the ions such as $\mathrm{SO}_{4}{ }^{2-}, \mathrm{NO}_{3}{ }^{-}, \mathrm{Cl}^{-}$, etc. Sulfates are clearly the first option as they have been effectively used to produce graphite intercalation compound using the electrochemical method. The first report on electrochemical exfoliation of graphite in $\mathrm{Na}_{2} \mathrm{SO}_{4}$ electrolyte was in 1997 where the product was described as a colloidal solution [21]. Parvez et al. [20] employed different types of inorganic salts containing sulfate ions namely, $\mathrm{K}_{2} \mathrm{SO}_{4}, \mathrm{Na}_{2} \mathrm{SO}_{4}$ or $\left(\mathrm{NH}_{4}\right)_{2} \mathrm{SO}_{4}$. They showed that the sulfate based salts can efficiently exfoliate the graphite into graphene with a high carbon/oxygen $(\mathrm{C} / \mathrm{O})$ ratio of 17.2. Zhang et al. reported the application of an electrolyte containing $\mathrm{Na}_{2} \mathrm{SO}_{4}-\mathrm{FeSO}_{4}$ to produced $\mathrm{Fe}_{2} \mathrm{O}_{3} /$ graphene. Their method leads to graphene with thickness of 1-2 layer with an electrical conductivity of $250 \mathrm{~S} / \mathrm{m}$ [22]. Zhao et al. demonstrated the application of ethylammonium nitrate or ammonium nitrate as electrolyte for the electrochemical exfoliation of graphite to obtain nitrogen-doped graphene. However, poor quality of the produced graphene (i.e. ca. 9 graphene layer thickness), led to relatively poor electrocatalytic activity $[13,15]$. Lou et al. reported the production of nitrogen doped graphene using electrochemical exfoliation of graphite in a mixture of $\left(\mathrm{NH}_{4}\right)_{2} \mathrm{SO}_{4}$ and $\mathrm{NH}_{3}$. They claimed that the nitrogen doped graphene obtained had an average thickness of $1.9 \mathrm{~nm}$ and a maximum thickness of $3.5 \mathrm{~nm}$ [23]. A two-step approach including electrochemical intercalation and oxidation of graphite has also been introduced [21-22]. For instance, Cao et al. [24] synthesized graphene oxide by initially intercalating the graphite in concentrated $\mathrm{H}_{2} \mathrm{SO}_{4}$, followed by an exfoliation step using $\left(\mathrm{NH}_{4}\right)_{2} \mathrm{SO}_{4}$ aqueous electrolyte. They found that their method leads to production of graphene oxide (GO) with high yield (> $70 \mathrm{wt} \%$ ) and good quality (> 90\% monolayer). 
The lifespan of graphene-based materials can be significantly reduced when they are utilized in high-temperature applications, as carbon may combust when exposed to such an oxidative environment [4]. Thus, enhancing the stability of graphene-based materials against oxidation is important to maximize their potential applications. However, only a few studies have been devoted to thermal stability of graphene so far [25-27]. Two main approaches have been introduced in this regard: in the first method, the surface is covered with another material which acts as a diffusion barrier to the oxidant [28]. Suvorov and et al. [29] studied the surface covering of corundumgraphite using different coatings containing $\mathrm{P}_{2} \mathrm{O}_{5}$. They inferred that the coating avoids the contact of the surface with oxygen and delays the oxidation. In the second method, the active site can be blocked using boron and/or phosphorous, which act as an oxidation resistant complex on the surface of the material (active site poisoning) [26-28,30-32]. It has been suggested that protective inhibitors, including adsorbed phosphate functional groups, provide a less reactive complex. These inhibitors, which attach to the edge of carbon materials, suppress the oxidation process. $\mathrm{C}-\mathrm{O}-\mathrm{PO}_{3}$ and $\mathrm{C}-\mathrm{OPOCl} \mathrm{P}_{2}$ complexes are the two most common phosphate groups which can suppress oxidation of carbon active sites [28,33]. McKee et al. [33] demonstrated that phosphorous groups bonded to the $\{101\}$ faces of graphite through $\mathrm{C}-\mathrm{O}-\mathrm{P}$ bonds, hindering the graphite oxidation. Oh and Rodriguez [34] functionalized graphite using a $0.2 \%$ aqueous solution of methyl-phosphonic acid and their findings revealed that there was no oxidation below $830{ }^{\circ} \mathrm{C}$. However, it should be mentioned that these approaches added an extra step to the synthesis of a thermally stable graphene.

To address these issues, we propose a one-step, safe, and facile approach to synthesize thermally stable graphene with fewer defects using electrochemical exfoliation of graphite in a single or mixed inorganic electrolytes. To investigate the effect of inorganic electrolytes on the 
properties of the produced graphene, we employed a range of electrolytes, namely: $\mathrm{Na}_{2} \mathrm{SO}_{4}$, $\left(\mathrm{NH}_{4}\right)_{2} \mathrm{SO}_{4}, \mathrm{NH}_{4} \mathrm{NO}_{3},\left(\mathrm{NH}_{4}\right)_{2} \mathrm{HPO}_{4}$, and mixtures of $\left(\mathrm{NH}_{4}\right)_{2} \mathrm{SO}_{4}$ and $\left(\mathrm{NH}_{4}\right)_{2} \mathrm{HPO}_{4}$. Our hypothesis was that utilizing an aqueous $\left(\mathrm{NH}_{4}\right)_{2} \mathrm{HPO}_{4}$ electrolyte, alone or in combination with sulfate or nitrate salts in the electrolyte, would lead to formation of phosphorous functional groups at the surface of graphene sheets, which can hinder the further oxidation of the surface.

\section{Experimental}

Electrochemical exfoliation of graphite was performed in a two-electrode configuration using platinum wire as the counter electrode (cathode) and a flexible graphite sheet (graphiteestore, INTRS-GSSM316) as the working electrode (anode) as shown in Figure 1 [18-22]. Different types of aqueous inorganic salt were examined as electrolyte solutions in order to obtain EEG with different chemical and physical properties (e.g. amount of nitrogen doping, $\mathrm{C} / \mathrm{O}$ ratio, the degree of disorder as indicated by the Raman spectra (intensity ratio of the D-band to G-band, $I_{D} / I_{G}$, etc.). $0.1 \mathrm{M}$ aqueous solution of inorganic salts used as electrolytes included $\left(\mathrm{Na}_{2}\right) \mathrm{SO}_{4},\left(\mathrm{NH}_{4}\right) \mathrm{NO}_{3}$, $\left(\mathrm{NH}_{4}\right)_{2} \mathrm{SO}_{4},\left(\mathrm{NH}_{4}\right)_{2} \mathrm{HPO}_{4}$, as well as mixtures of $0.1 \mathrm{M}$ aqueous solution salts (mol. \%): $\left[\left(\mathrm{NH}_{4}\right)_{2} \mathrm{SO}_{4} 90 \%+\left(\mathrm{NH}_{4}\right)_{2} \mathrm{HPO}_{4} 10 \%\right],\left[\left(\mathrm{NH}_{4}\right)_{2} \mathrm{SO}_{4} 70 \%+\left(\mathrm{NH}_{4}\right)_{2} \mathrm{HPO}_{4} 30 \%\right],\left[\left(\mathrm{NH}_{4}\right)_{2} \mathrm{SO}_{4} 50 \%+\right.$ $\left.\left(\mathrm{NH}_{4}\right)_{2} \mathrm{HPO}_{4} 50 \%\right]$. The Pt-wire and graphite foil $\left(5 \mathrm{~cm}^{2}\right)$ were placed at a distance of $2 \mathrm{~cm}$ apart. A $100 \mathrm{ml}$ volume of electrolyte containing the inorganic salt with different compostions was used in the electrolytic cell.

A contant voltage of $10 \mathrm{~V}$ was applied to the cell until the exfoliation was complete and current dropped to $0 \mathrm{~A}(3-4 \mathrm{~h})$. After the electrochemical exfoliation, the resultant product was filtered and washed with DI water using a vacuum filtration setup using an HTTP membrane. 
The obtained material was sonicated and dispersed in DI water using a bath sonicatior for $1 \mathrm{~h}$. The sample was left to settle for $24 \mathrm{~h}$ to separate the large unexfoliated particles. The exfoliated product was collected by vacuum filtration, washed several times to remove any residual salt, and then redispersed in water using bath sonication for $1 \mathrm{~h}$. The synthesis yield for different EEGs was calculated based on the concentration of the final suspension and it was determined relative to the total weight of the starting graphite electrodes by weighing the precipitates and dispersed EEG.

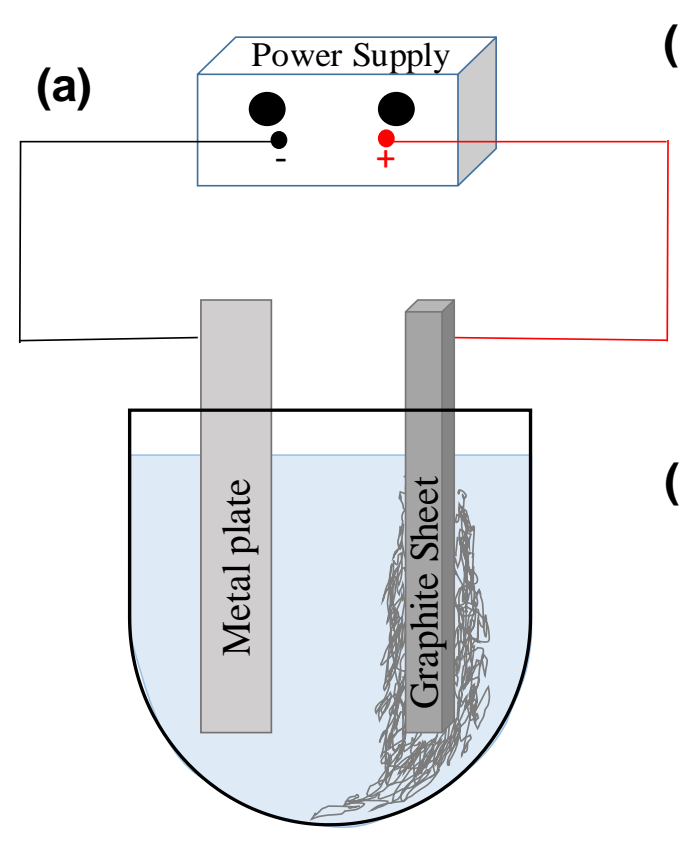

(b)

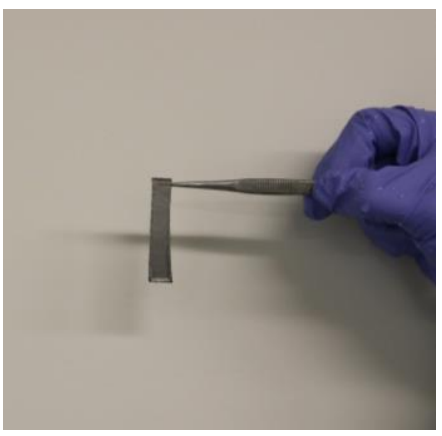

(c)

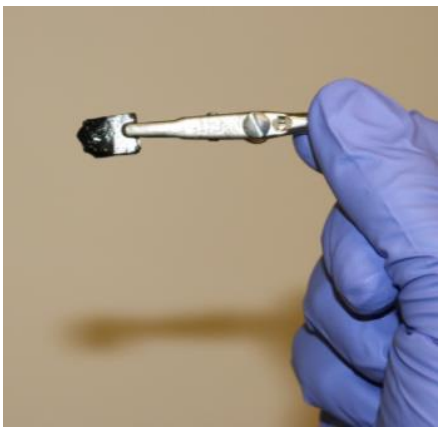

Figure 1 - (a) Schematic diagram of the synthesis set-up, photographs of graphite electrodes (b) before and (c) after electrochemical exfoliation.

\section{Characterization}

Transmission electron microscopy (TEM) was used to characterize the morphology and nanostructure of the EEGs. The TEM used was a Tecnai TF20 G2 FEG-TEM (FEI, Hillsboro, Oregon, USA) instrument operating at $200 \mathrm{kV}$ acceleration voltage with a standard single-tilt holder. Raman spectra were recorded on a WITec alpha 300 R Confocal Raman Microscope 
(WITec GmbH, Germany) using a 532-nm laser. In order to evaluate the elemental composition, X-ray photon spectroscopy (XPS) was performed using an ESCALAB 250Xi (Thermo Scientific) on different synthesized EEGs.

Atomic force microscopy (AFM) was utilized to measure the thickness of the exfoliated sheets. For this purpose, samples were diluted 500 times by volume prior to being drop-casted onto freshly cleaved mica (Ted Pella Inc). Topography images were obtained using a Keysight 5500 AFM in contact mode and post-processed by Gwyddion software [35]. EEG sheet size, elemental composition and electrode struture were charactrzied using an FEI Quanta 250 FEG field emission scanning electron microscope. To do so, aqueous dispersions of the different EEGs were diluted with pure ethanol, drop-cast onto the surface of a silicon wafer, and then dried at $70{ }^{\circ} \mathrm{C}$. A thermogravimetric analyzer (TA Instruments, Q500) was used to obtain TGA data under nitrogen and air atmospheres from room temperature to $900{ }^{\circ} \mathrm{C}$, with a $10{ }^{\circ} \mathrm{C} \mathrm{min}^{-1}$ heating rate.

\section{Results and Discussion}

The yield of EEG obtained was $60 \pm 6 \%$ in all cases, and there was no significant difference in the yield for the EEG produced in the different electrolytes studied. The rate of production of EEG, calculated based on the area of graphite foil, the mass of EEG produced per batch, and the exfoliation time, was also independent of the electrolyte used, in the range $250 \pm 25 \mathrm{~g} \mathrm{~h}^{-1} \mathrm{~m}^{-2}$.

The number of layers and lateral size of the as-prepared EEGs were characterized by transmission electron and atomic force microscopy. Figure 2 shows the TEM images of $\left(\mathrm{NH}_{4}\right)_{2} \mathrm{SO}_{4},\left(\mathrm{NH}_{4}\right)_{2} \mathrm{HPO}_{4}$, and 70-30 mixed $\left(\mathrm{NH}_{4}\right)_{2} \mathrm{SO}_{4} /\left(\mathrm{NH}_{4}\right)_{2} \mathrm{HPO}_{4}$ electrolytes EEGs and the corresponding selected area electron diffraction (SAED) patterns. The typical 6-fold symmetric diffraction patterns with strong spots indicate the crystalline nature of the EEGs [24,36]. 
Furthermore, a more intense diffraction spot from 0-110 plane compared to 1-210 suggests the presence of monolayer EEG [24,36-38]. Analysis of SAED patterns for EEG sheets reveals that using $\left(\mathrm{NH}_{4}\right)_{2} \mathrm{SO}_{4}$ is highly efficient for the exfoliation process when the number of single layer EEG sheet comes to account (Figure S1). On the other hand, the diffraction spot at 1-210 had higher intensity than that for the $0-110$ plane for $\mathrm{Na}_{2} \mathrm{SO}_{4}$ (Figure S1) and $\left(\mathrm{NH}_{4}\right)_{2} \mathrm{HPO}_{4}$ electrolytes, suggesting that these EEG sheets had a significant amount of multilayer EEG.

Raman spectroscopy was employed to quantify the defects in the prepared EEG coated on a silicon wafer. The Raman spectra of the graphene is typically characterized by the D-band (ca. $1350 \mathrm{~cm}^{-1}$ ) and G-band (ca. $1580 \mathrm{~cm}^{-1}$ ). D band arises from breathing mode of the $\mathrm{sp}^{2}$ carbon atoms as a result of defects in the graphene structure (attributed to functional groups or structural disorder), and the $\mathrm{G}$ band comes from in-plane vibration of $\mathrm{sp}^{2}$ carbon atoms. The intensity ratio of the D-band to G-band, $\left(I_{D} / I_{G}\right)$ can typically be applied as a criterion to identify the degree of disorder in the graphene [39].

Figure 3 depicts the Raman mapping of the intensity ratio $I_{D} / I_{G}$ (the Raman spectrum was obtained at each pixel and assigning a color depending on the measured $I_{D} / I_{G}$ ratio) for electrochemically exfoliated graphenes using each of the salts. The contrast in the blue (darker blue) in Figure 3 (b) and (d) demonstrates a lower intensity ratio of $I_{D} / I_{G}$, indicating fewer defects. The probability distribution of the $I_{D} / I_{G}$ ratio was calculated for each sample and is shown in the figure. The sample prepared using $\left(\mathrm{NH}_{4}\right)_{2} \mathrm{HPO}_{4}$ showed an $I_{D} / I_{G}$ ratio of $\sim 0.25$. The $I_{D} / I_{G}$ changes depending on the salt used, with the amount of disorder increasing as follows: $\left(\mathrm{NH}_{4}\right)_{2} \mathrm{HPO}_{4}<$ $\left(\mathrm{NH}_{4}\right)_{2} \mathrm{SO}_{4}<\mathrm{Na}_{2} \mathrm{SO}_{4}<\mathrm{NH}_{4} \mathrm{NO}_{3}$. 
(a)

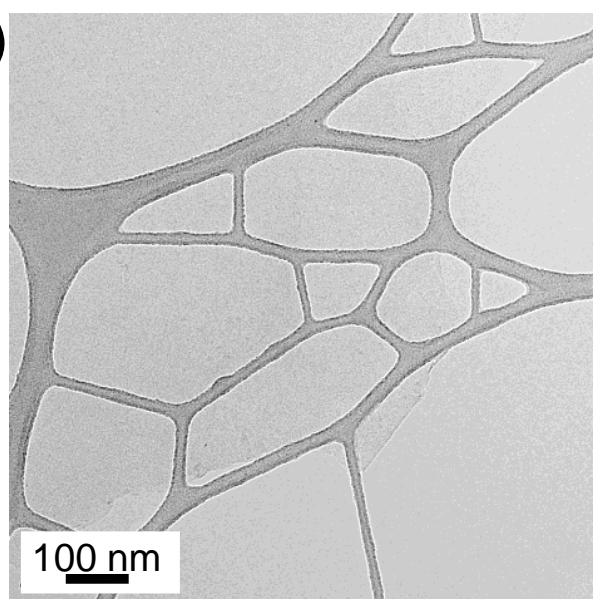

(c)

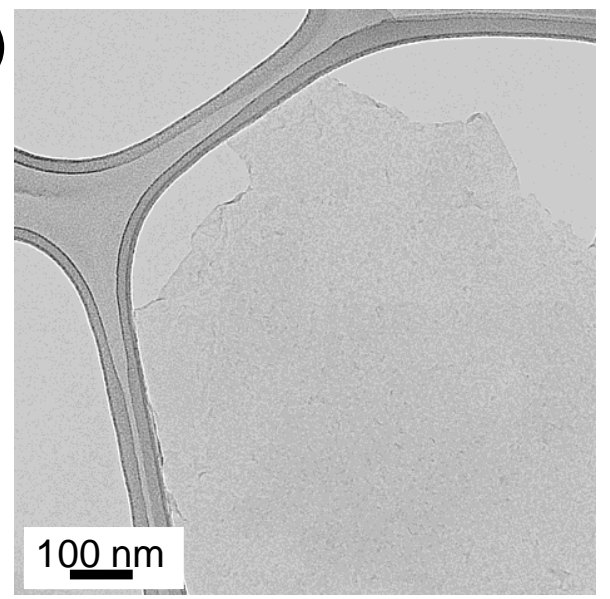

(e)

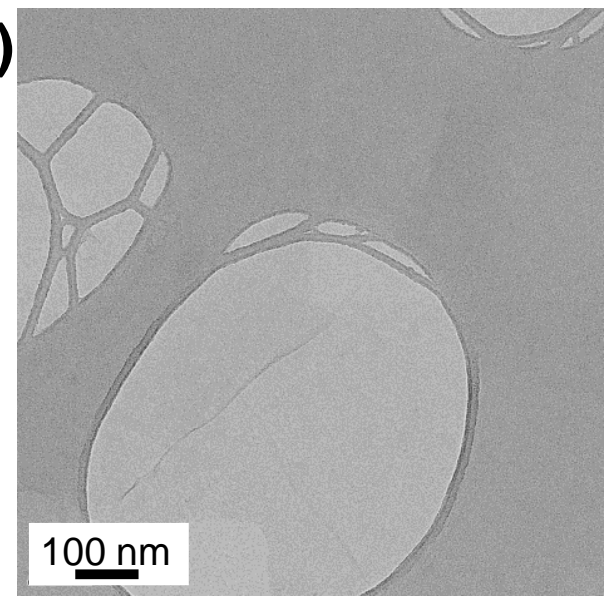

(b)

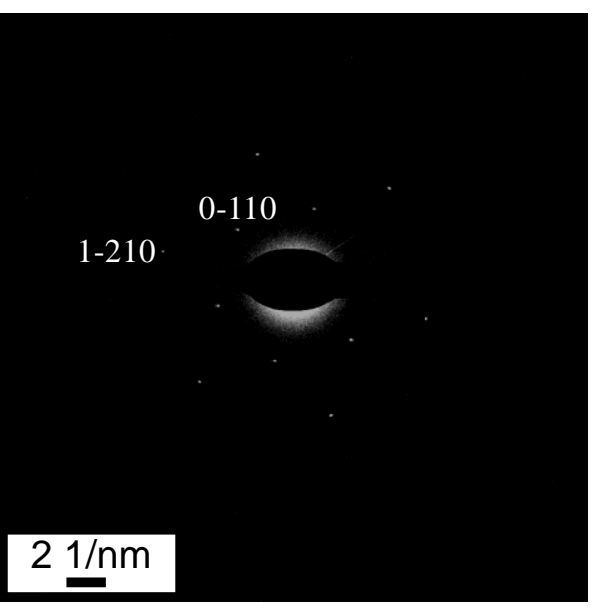

(d)

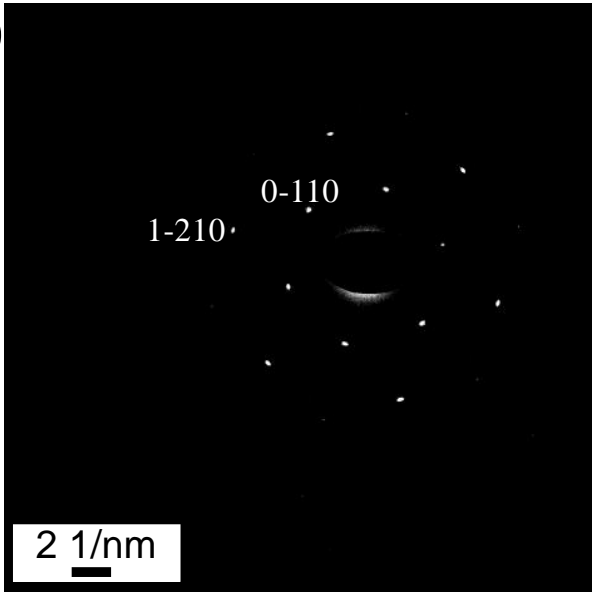

(f)

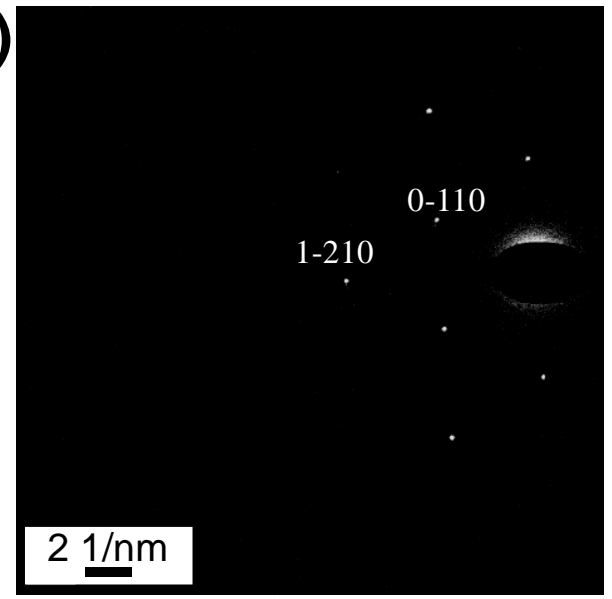

Figure 2. TEM images and the corresponding SAED patterns for EEG obtained using (a \& b) $\left(\mathrm{NH}_{4}\right)_{2} \mathrm{SO}_{4},(\mathrm{c} \& \mathrm{~d})\left(\mathrm{NH}_{4}\right)_{2} \mathrm{HPO}_{4}$, and (e \& f) 70-30 mixed $\left(\mathrm{NH}_{4}\right)_{2} \mathrm{SO}_{4} /\left(\mathrm{NH}_{4}\right)_{2} \mathrm{HPO}_{4}$ electrolytes. 

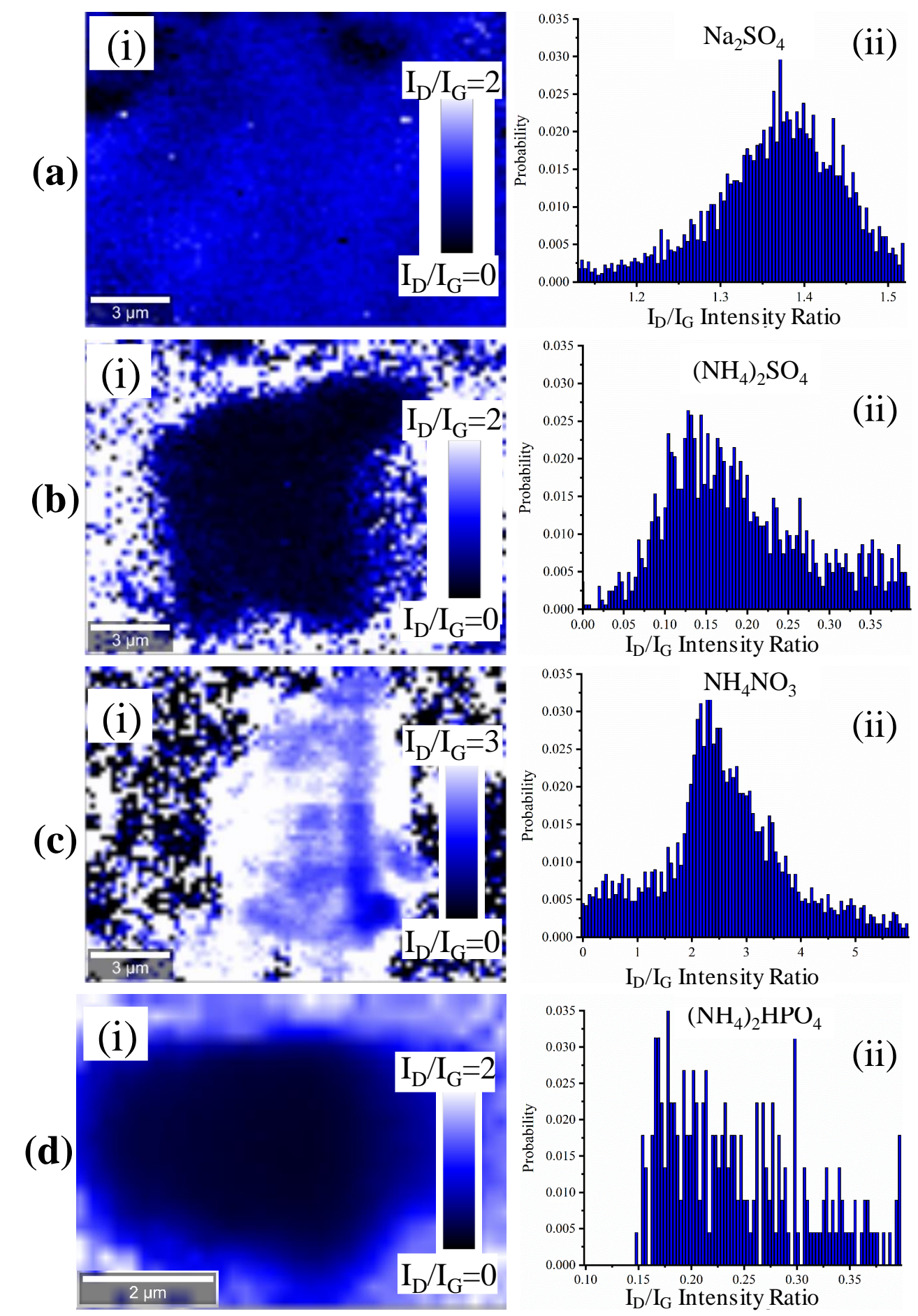

Figure 3. Confocal Raman spectroscopy data for EEG synthesized in electrolytes using 0.1 $\mathrm{M}$ of (a) $\mathrm{Na}_{2} \mathrm{SO}_{4}$, (b) $\left(\mathrm{NH}_{4}\right)_{2} \mathrm{SO}_{4}$, (c) $\mathrm{NH}_{4} \mathrm{NO}_{3}$, and (d) $\left(\mathrm{NH}_{4}\right)_{2} \mathrm{HPO}_{4}$. A $2 \mathrm{D}$ map of the distribution of the $I_{D} / I_{G}$ intensity ratio on a EEG nanosheet is shown for each material (i), as well as the corresponding probability distribution of $I_{D} / I_{G}$. 
The increased disorder corresponds to increasing defects, doping and functionalization in the EEG. The observation of fewer defects for EEG prepared using $\left(\mathrm{NH}_{4}\right)_{2} \mathrm{HPO}_{4}$ is consistent with the results obtained by Marcano et al. [40], who used a 9:1 mixture of $\mathrm{H}_{2} \mathrm{SO}_{4}: \mathrm{H}_{3} \mathrm{PO}_{4}$ to obtain high-quality graphene oxide using the Hummers method. Higginbotham et al. [41] in a similar study also used trifluoroacetic acid and phosphoric acid $\mathrm{H}_{3} \mathrm{PO}_{4}$ in the Hummers method to synthesize graphene oxide nanoribbons. They showed that addition of the second acid $\left(\mathrm{H}_{3} \mathrm{PO}_{4}\right)$ prevents excessive oxidation and hole formation on the basal planes of the graphene, leading to the fewer defects. It is important to note that all these studies used acids as compared to mild salts adopted here.

Figure S2a shows the Raman spectra of EEGs prepared using different salts. Unlike the EEGs exfoliated in $\left(\mathrm{NH}_{4}\right)_{2} \mathrm{HPO}_{4}$ and $\left(\mathrm{NH}_{4}\right)_{2} \mathrm{SO}_{4}$, the samples prepared using $\mathrm{Na}_{2} \mathrm{SO}_{4}$ and $\mathrm{NH}_{4} \mathrm{NO}_{3}$ have a broad peak G band from 1580-1630 implying incomplete, non-uniform exfoliation of graphite into graphene. A red shift of the G-band to $1612 \mathrm{~cm}^{-1}$ indicates graphene sheets with only one adjacent intercalant, while a shift to $1625 \mathrm{~cm}^{-1}$ suggests graphene layers between two intercalant layers $[42,43]$. Figure S2b also shows the Raman spectra of EEGs prepared using electrolytes containing a mixture of $\left(\mathrm{NH}_{4}\right)_{2} \mathrm{HPO}_{4}$ and $\left(\mathrm{NH}_{4}\right)_{2} \mathrm{SO}_{4}$. A similar Raman profile is observed with a decreased intensity of the D-peak as compared to the EEG synthesized from pure $\left(\mathrm{NH}_{4}\right)_{2} \mathrm{HPO}_{4}$, and $\left(\mathrm{NH}_{4}\right)_{2} \mathrm{SO}_{4}$ electrolytes. The results confirms that the addition of even a low concentration of $\left(\mathrm{NH}_{4}\right)_{2} \mathrm{HPO}_{4}$, to the $\left(\mathrm{NH}_{4}\right)_{2} \mathrm{SO}_{4}$ electrolyte (in a ratio of 1:9) can prevent excessive oxidation on the surface which reduces the defects formation on the basal plane.

The chemical nature, composition, and heteroatom doping species of the as-synthesized EEG was investigated by XPS. The survey scans of all exfoliated graphene samples (see Figure S3a) confirms the presence of oxygen, suggesting partial oxidation for all EEGs, and nitrogen 
doping for EEGs synthesized with $\left(\mathrm{NH}_{4}\right)_{2} \mathrm{SO}_{4}, \mathrm{NH}_{4} \mathrm{NO}_{3}$, and $\left(\mathrm{NH}_{4}\right)_{2} \mathrm{HPO}_{4}$. In addition, the survey indicates the presence of sulphur for EEGs synthesized with $\mathrm{Na}_{2} \mathrm{SO}_{4}$, and $\left(\mathrm{NH}_{4}\right)_{2} \mathrm{SO}_{4}$ electrolytes and phosphorous for $\left(\mathrm{NH}_{4}\right)_{2} \mathrm{HPO}_{4}$ electrolyte. The survey scans for the EEG from mixture of electrolytes demonstrates a decrease in the oxygen content and a corresponding increase in the carbon and nitrogen content suggesting higher level of nitrogen doping. It is noteworthy that using a mixture of electrolytes results in a triple heteroatom doping on the graphene including nitrogen, sulphure, and phosphorous. This indicates another advantage of the proposed approach when heteroatom doping comes to account. In order to provide further insight into the chemical characteristics of some selected EEGs, high resolution scans of C1s, N1s, S2p and P2p are shown in Figure 4. The C1s peaks of the EEG from single electrolytes was deconvoluted into four peaks at binding energy values of ca. $284.5 \mathrm{eV}, 258.3 \mathrm{eV}, 287.8 \mathrm{eV}$, and $289.2 \mathrm{eV}$, corresponding to $\mathrm{C}-\mathrm{C}$ graphitic $\left(\mathrm{sp}^{2}\right)$ carbon, $\mathrm{C}-\mathrm{O}, \mathrm{C}=\mathrm{O}$, and $\mathrm{O}-\mathrm{C}=\mathrm{O}$ respectively $[20,24,36,39,44,45]$. An additional peak in the case of the $\mathrm{N}$-doped graphene at ca. $286.2 \mathrm{eV}$, corresponds to the $\mathrm{C}-\mathrm{O}$ or $\mathrm{C}-\mathrm{N}$ bonds. 
(a)
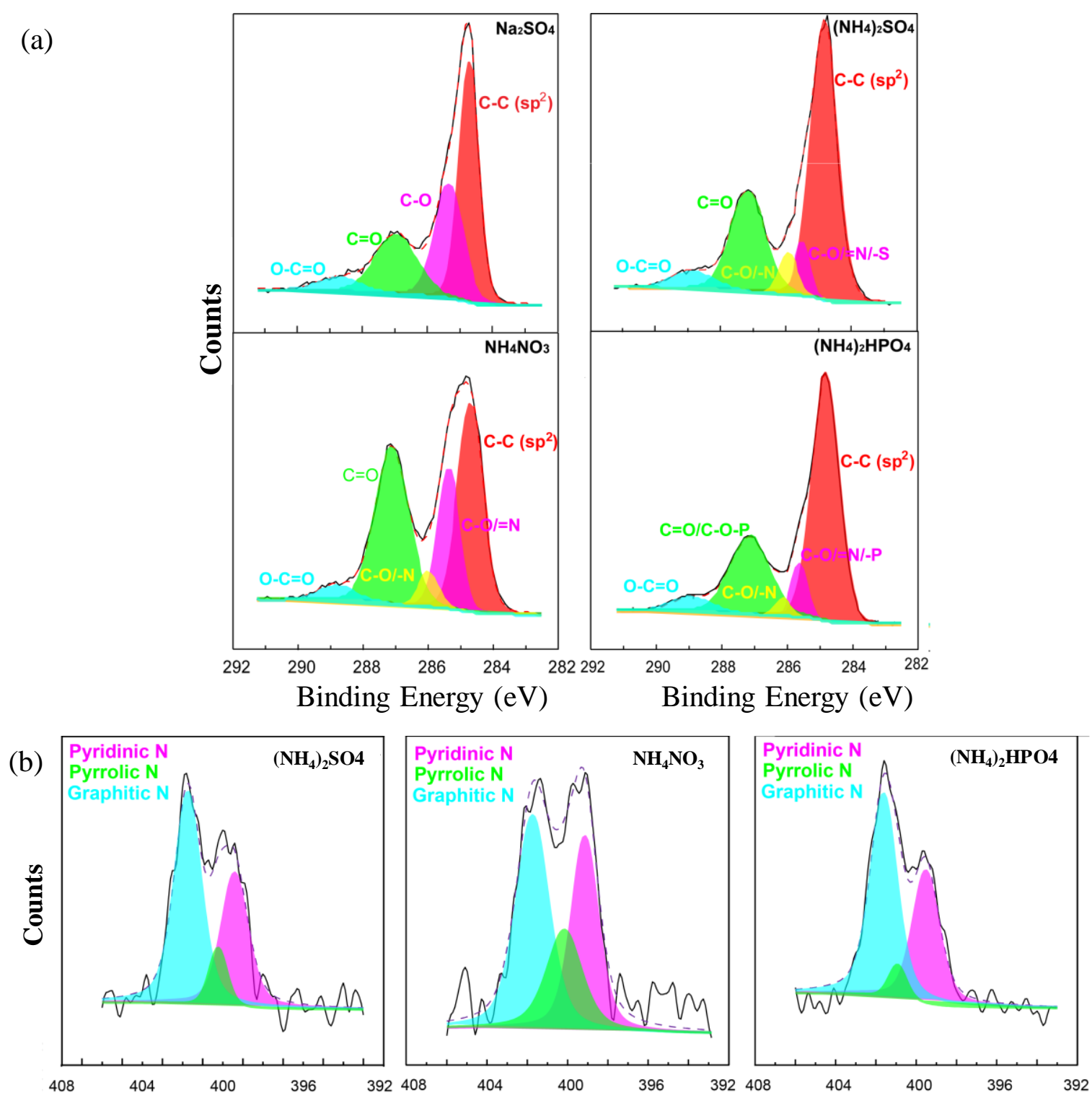

Binding Energy (eV)

Binding Energy (eV)

Binding Energy (eV)

(c)

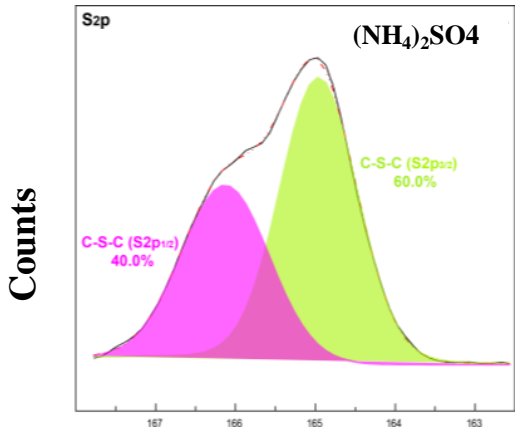

Binding Energy (eV)

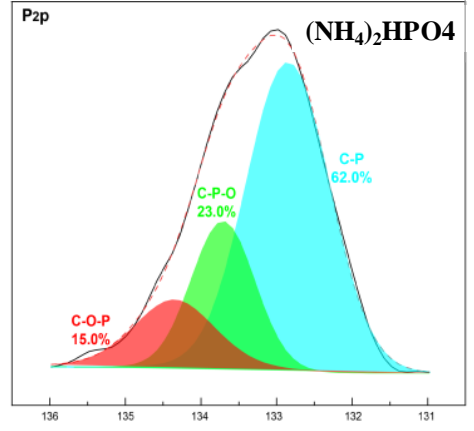

Binding Energy (eV)

Figure 4. High resolution XPS scans of synthesized EEGs from single electrolytes depicting the (a) C1s, (b) N1s, (c) S2p, and P2p spectra 

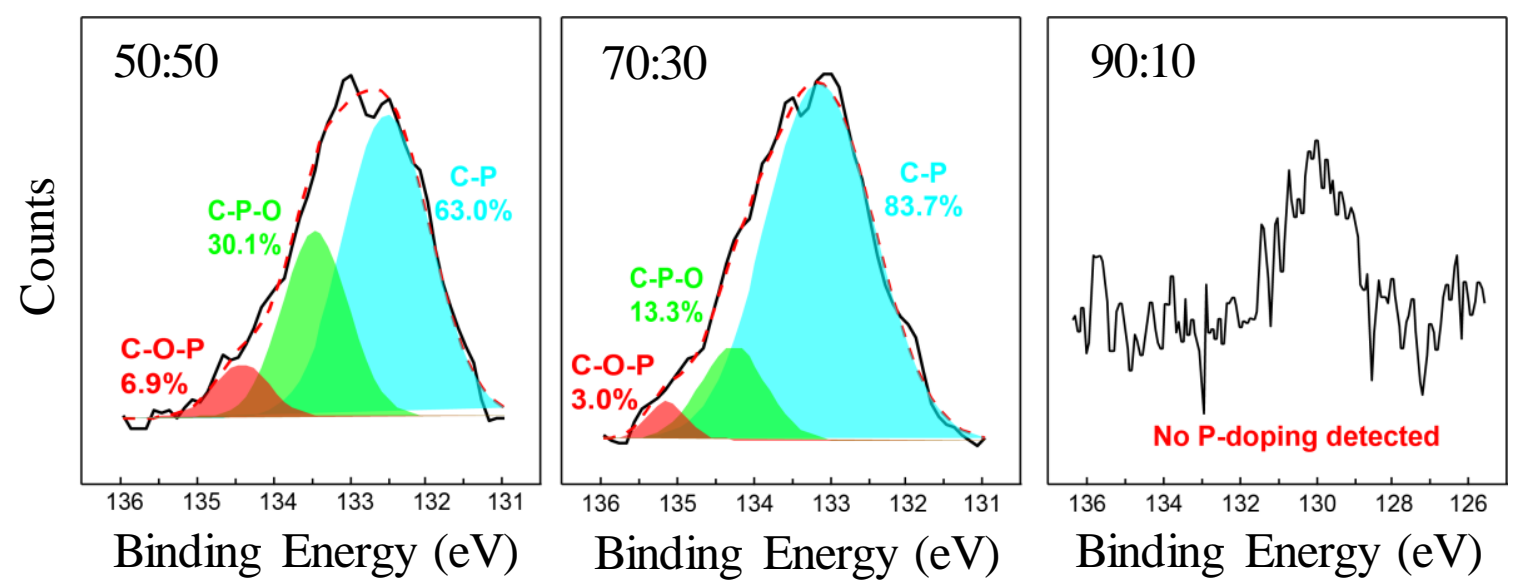

Figure 5. High resolution XPS scans of synthesized EEGs from mixed electrolyte depicting high resolution P2p spectra for the $\left(\mathrm{NH}_{4}\right)_{2} \mathrm{SO}_{4}+\left(\mathrm{NH}_{4}\right)_{2} \mathrm{HPO}_{4}$ electrolyte mixture in Mol.\% of 50-50, 70-30, 90-10.

The deconvolution of the N1s peak three degenerate peaks, at 399.2, 400.3, and $401.7 \mathrm{eV}$ corresponding to the pyridinic $\mathrm{N}$, pyrrolic $\mathrm{N}$, and graphitic $\mathrm{N}$, respectively $[44,46,47]$, are evident in the spectra. Graphitic N-doping can improve the electrical conductivity of the graphene oxide while pyrrolic $\mathrm{N}$ can create abundant extrinsic defects and active sites on the graphene basal plane. The high resolution spectra of N1s (Figure 4b) shows EEG-(NH$)_{2} \mathrm{HPO}_{4}$ had the highest atomic percentage of graphitic nitrogen $(56.6 \%$, see Table S1).

The high resolution of the $\mathrm{S} 2 \mathrm{p}$ spectrum for EEG prepared using $\left(\mathrm{NH}_{4}\right)_{2} \mathrm{SO}_{4}$ can be decomposed into two different peaks at $164.9 \mathrm{eV}$ and $166.1 \mathrm{eV}$ which is assigned to $\mathrm{S} 2 \mathrm{p}_{3 / 2}$ and $\mathrm{S} 2 \mathrm{p}_{1 / 2}$, respectively [48-50]. $\mathrm{S} 2 \mathrm{p}_{3 / 2}$ and $\mathrm{S} 2 \mathrm{p}_{1 / 2}$ peaks account for most of the $\mathrm{S}$ content, confirming the integration of $\mathrm{S}$ atoms into the graphene lattice of EEG-(NH$)_{2} \mathrm{SO}_{4}$.

Based on the deconvolution of the high resolution of $\mathrm{P} 2 \mathrm{p}$, three peaks can be fitted at 132.9eV, $133.7 \mathrm{eV}$, for $\mathrm{P}-\mathrm{C}, \mathrm{C}-\mathrm{P}-\mathrm{O}$, and $\mathrm{C}-\mathrm{O}-\mathrm{P}$ bonding configuration, respectively [51-56]. The main component of the $\mathrm{P} 2 \mathrm{p}$ is $\mathrm{P}-\mathrm{C}$ bonding, suggesting that $\mathrm{P}$ is successfully incorporated into the 
graphene lattice. The peaks at higher binding energy are attributed to P-containing functional groups including $\mathrm{C}-\mathrm{PO}_{3}, \mathrm{C}_{2} \mathrm{PO}_{2}, \mathrm{C}-\mathrm{O}-\mathrm{PO}_{3},(\mathrm{CO})_{3} \mathrm{PO}_{2}, \mathrm{C}-\mathrm{O}-\mathrm{PO}(\mathrm{OH})_{2}$, and $(\mathrm{CO})_{2} \mathrm{PO}$ [55-57]. A co-doped graphene structure combining nitrogen and phosphorous is a promising material for several applications due to its catalytic efficiency, high-temperature stability, and electro-oxidation resistance $[54,56,57]$.

It is necessary to point out here that although the XPS survey in Figure S3 (a) suggests that EEG-(NH$)_{2} \mathrm{HPO}_{4}$ to contain the highest atomic percentage of oxygen, this is however incorrect. The high resolution P2p spectra (Figure 4c) proposes some oxygen contribution from the phosphorous-oxygen functional groups such as $\mathrm{C}-\mathrm{PO}_{3}, \mathrm{C}_{2} \mathrm{PO}, \mathrm{C}-\mathrm{O}-\mathrm{PO}_{3},(\mathrm{CO})_{3} \mathrm{PO}_{2}, \mathrm{C}-\mathrm{O}-$ $\mathrm{PO}(\mathrm{OH})_{2}$, and $(\mathrm{CO})_{2} \mathrm{PO}$ rather than only the oxidation of the graphite. This claim is further supported by the elemental content obtained from deconvolution of the XPS data (Table S1). It was observed that EEG-(NH$)_{2} \mathrm{HPO}_{4}$ had the highest graphitic carbon content ( 58\%). Thus, from the C1s high resolution spectra (Figure 4, Table S1), the highest oxygen content was obtained for EEG-NH $\mathrm{NO}_{3}$, implying a higher degree of oxidation.

The oxygen groups at the surface of EEGs originate from the oxidation of graphite during the electrochemical exfoliation. In addition, EEGs prepared with $\left(\mathrm{NH}_{4}\right)_{2} \mathrm{HPO}_{4}$ electrolyte have the highest nitrogen doping content $(\sim 1.9 \%)$ as well as significant amount of phosphorous doping $(\sim 0.7 \%)$ as observed in Figure S3(a). The XPS C1s spectrum of the EEG-NH $\mathrm{NHO}_{3}$ was characterized by a highly intense peak at $287.8 \mathrm{eV}$, corresponding to the formation of $\mathrm{C}=\mathrm{O}$ and - $\mathrm{COO}$ - groups which can break into $\mathrm{C}-\mathrm{C}$ bonds, leaving permanent vacancies/hole defects in the graphene structure. This confirms the high degree of disorder (from the Raman results) and oxidation during the exfoliation for graphite in the $\mathrm{NH}_{4} \mathrm{NO}_{3}$ electrolyte, where we have the lowest number of $\mathrm{C}-\mathrm{C}$ bonds. The results also suggest less damage to the graphitic structure in the EEG 
synthesized with $\left(\mathrm{NH}_{4}\right)_{2} \mathrm{HPO}_{4}$ and $\left(\mathrm{NH}_{4}\right)_{2} \mathrm{SO}_{4}$ compared to $\mathrm{NH}_{4} \mathrm{NO}_{3}$ and $\mathrm{Na}_{2} \mathrm{SO}_{4}$, based on the intensity of the $\mathrm{C}-\mathrm{C}$ peaks. The difference between the $\mathrm{NH}_{4} \mathrm{NO}_{3},\left(\mathrm{NH}_{4}\right)_{2} \mathrm{HPO}_{4}$ and $\left(\mathrm{NH}_{4}\right)_{2} \mathrm{SO}_{4}$ can be explained by the rate of electrochemical exfoliation. As can be seen in Videos 1-4 (in the Supporting Info), the intercalated graphite leaves the surface of the graphite quickly when either $\left(\mathrm{NH}_{4}\right)_{2} \mathrm{HPO}_{4}$ or $\left(\mathrm{NH}_{4}\right)_{2} \mathrm{SO}_{4}$ solution was used as the electrolyte. On the other hand, when the $\mathrm{NH}_{4} \mathrm{NO}_{3}$ solution was used as the electrolyte, intercalated graphite stays at the surface of graphite for a longer time which promotes the further oxidation of the graphene. Furthermore, the high intensity of the peak assigned to pyrrolic $\mathrm{N}$ for $\mathrm{EEG}$ exfoliated in $\mathrm{NH}_{4} \mathrm{NO}_{3}$ suggests a a greater number of defects for this EEG.

Figure S3 (b-d) illustrates the XPS analysis for EEGs synthesized with mixed electrolytes. The XPS analysis displays similar peaks components to EEGs synthesized from single electrolytes. A comparison of the graphitic carbon (C-C) content also shows a general improvement in the atomic percentage. For mixed electrolytes, tertiary doping of nitrogen, sulphur, and phosphorous was observed (see Figure S3(b-c)). Deconvolution of N1s for these EEGs indicates that adding $\left(\mathrm{NH}_{4}\right)_{2} \mathrm{HPO}_{4}$ decreases the pyridinic nitrogen and increases the amount of graphitic nitrogen (Figure S3d). The high resolution of P2p spectrum also indicates the formation of phosphorous functional groups on the surface of graphene oxides as well as $\mathrm{P}-\mathrm{C}$ bonds in the graphene lattice (See Figure 5). To confirm the XPS elemental composition, SEM elemental analysis on large scale EEG films was performed and similar results were obtained. Figure S4 demonstrates the homogeneous distribution of doped elements in the surface of the EEG films.

The lateral size for the synthesized EEGs sheet was measured using SEM (Figure S5 and S6). The average lateral sizes for the EEGs synthesized in different electrolytes are as follows: $\mathrm{Na}_{2} \mathrm{SO}_{4}=1.85 \mu \mathrm{m} ;\left(\mathrm{NH}_{4}\right)_{2} \mathrm{SO}_{4}=1.58 \mu \mathrm{m} ; \mathrm{NH}_{4} \mathrm{NO}_{3}=5.21 \mu \mathrm{m} ;$ and $\left(\mathrm{NH}_{4}\right)_{2} \mathrm{HPO}_{4}=2.36 \mu \mathrm{m}$. 
Analysis reveals that EEG particles synthesised in $\mathrm{NH}_{4} \mathrm{NO}_{3}$ had the largest lateral size. The relationship between the lateral size and the electrolyte salt is difficult to interpret, as many factors may be involved. However, the larger lateral size obtained with the $\mathrm{NH}_{4} \mathrm{NO}_{3}$ electrolyte may be due to the greater thickness of the EEG particles, owing to incomplete exfoliation. The thicker EEGs may be more mechanically robust and thus maintain a larger lateral size during the exfoliation and/or sonication. The lateral size may also be influenced by oxidation processes. In the presence of the $\left(\mathrm{NH}_{4}\right)_{2} \mathrm{HPO}_{4}$ excesive oxidation and digestion of the graphene sheets may be prevented, resulting in larger average lateral size in comparison to EEGs prepared in $\mathrm{Na}_{2} \mathrm{SO}_{4}$, and $\left(\mathrm{NH}_{4}\right)_{2} \mathrm{SO}_{4}$ electrolytes.

The thickness of the synthesized nanosheets was determined by extracting line profiles from AFM topography images as shown in Figure 6. For all the electrolytes studied, the thinnest nanosheets (assumed to be monolayer graphene) had thicknesses ranging from 1-1.2 nm. This is slightly higher than previously reported thicknesses of EEG monolayers of 0.7-0.9 nm on a silica substrate [20][58]. The difference can be attributed to the substrate (mica versus silica) and the mode of AFM imaging (contact mode versus AC mode). The image shown in Figure 6 indicates that the exfoliation was successful in yielding monolayer nanosheets. However, some multilayer sheets were also produced, which is in agreement with SAED results. The values next to each profile show the height between the solid and dashed line. Profile 1 shows a monolayer whose thickness is similar to the values reported for functionalized graphene (EEG) monolayers [20][58]. The overlapping of three monolayers can be seen in the middle of profile 2. Finally, in profile 3 , a bilayer sheet is covering a small area of a monolayer sheet. Further analysis of line profiles of samples prepared by different salts reveals that the distribution of the number of layers is directly affected by the type of electrolyte as shown in Figure 7. Interestingly, the use of a mixture of two 
salts increases the population of mono and bilayer sheets. Addition of $\left(\mathrm{NH}_{4}\right)_{2} \mathrm{HPO}_{4}$ to $\left(\mathrm{NH}_{4}\right)_{2} \mathrm{SO}_{4}$ as low as a 90-10 volume ratio leads to a significant increment of monolayer sheets. However, there is an optimum concentration ratio which gives the highest degree of exfoliation. This implies that there is a synergy between the sulphate and phosphate salts, leading to enhancement of exfoliation performance. It can be concluded from the results in the Figure 7 that using a mixed electrolyte with $70 \%\left(\mathrm{NH}_{4}\right)_{2} \mathrm{SO}_{4}$ provided better exfoliation characteristics with a higher proportion and distribution of single layer EEGs.

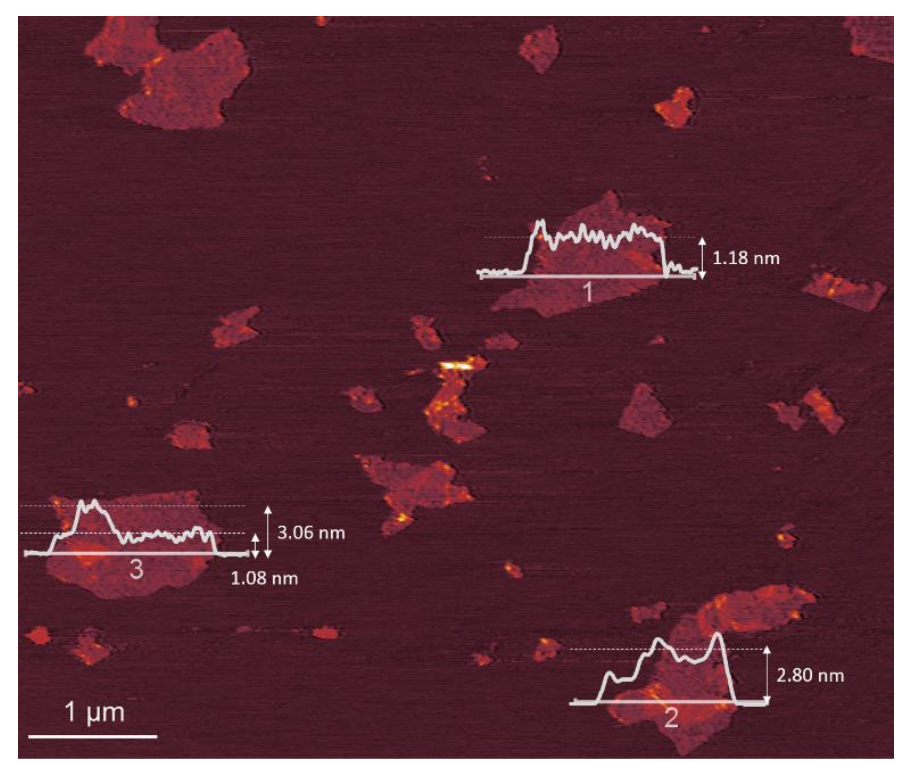

Figure 6. AFM topography image along with the selected line profiles of EEG sheets prepared by using a ratio of 70/30 of $\left(\mathrm{NH}_{4}\right)_{2} \mathrm{SO}_{4} /\left(\mathrm{NH}_{4}\right)_{2} \mathrm{HPO}_{4}$.

We speculate that employing $\left(\mathrm{NH}_{4}\right)_{2} \mathrm{SO}_{4}$ results in better exfoliation, due to enhanced intercalation, but may result in digestion of the thinner sheets. On the other hand, utilizing the $\left(\mathrm{NH}_{4}\right)_{2} \mathrm{HPO}_{4}$ may result in poor exfoliation, but the phosphate functional groups can protect the thin sheets from further oxidation. With an electrolyte containing a mixture of $\left(\mathrm{NH}_{4}\right)_{2} \mathrm{SO}_{4}$ and $\left(\mathrm{NH}_{4}\right)_{2} \mathrm{HPO}_{4}$, both optimal exfoliation (due to the presence of $\left.\left(\mathrm{NH}_{4}\right)_{2} \mathrm{SO}_{4}\right)$ and protection of further 
oxidation of the thiner sheets (due to presence of $\left.\left(\mathrm{NH}_{4}\right)_{2} \mathrm{HPO}_{4}\right)$ occur. An indepth and specialized investigation is needed to determine the nature of this synergy which is not in the scope of the present study.

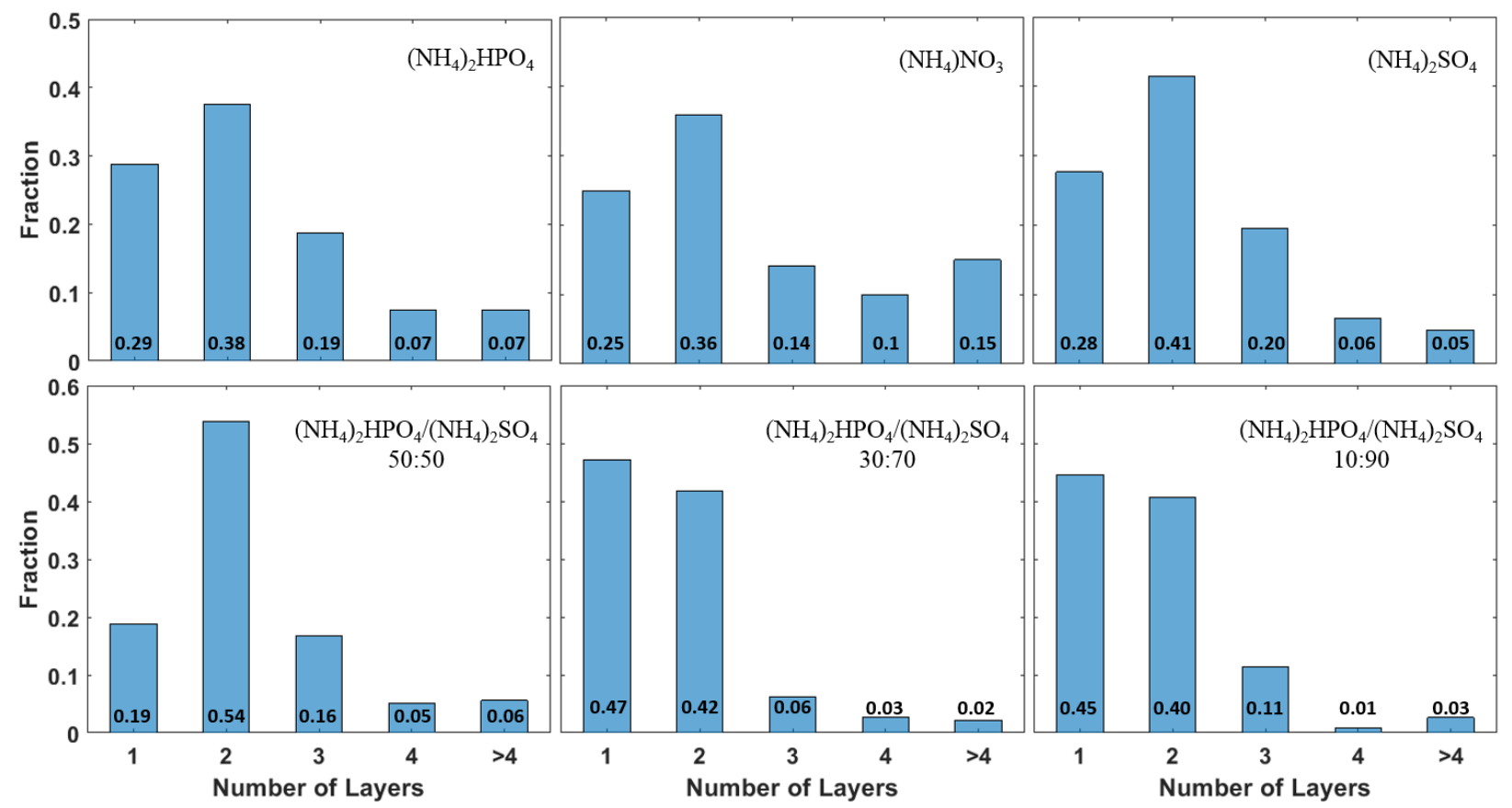

Figure 7. Histograms of number of layers for samples prepared using different salts. The values on each bar show the fraction of the corresponding group.

Thermo-gravimetric analysis (TGA) was performed in air to evaluate the high-temperature stability of the synthesized EEGs (Figure 8). The TGA results for all electrochemically exfoliated graphenes displayed three stages of mass loss: (i) the first stage occurs around $100{ }^{\circ} \mathrm{C}$ due to evaporation of absorbed water; (ii) the second stage occurs about $150-300{ }^{\circ} \mathrm{C}$ and can be attributed to the removal the of oxygen-containing functional groups from the basal planes and the edges of the EEG [59,60]; and (iii) the final stage of mass loss is associated with oxidation and degradation of the graphene material. 

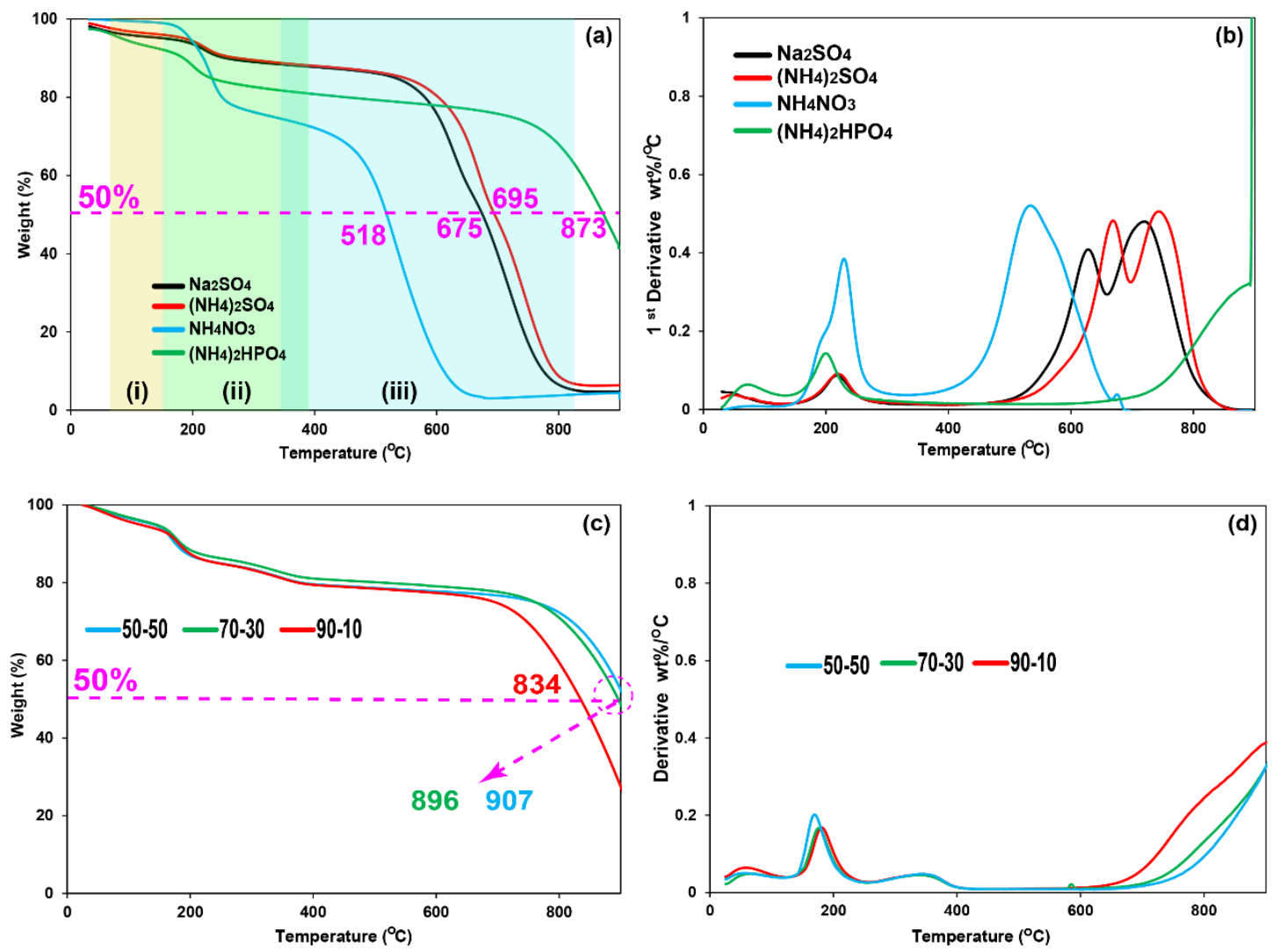

Figure 8. Thermo-gravimetric analysis; (a) weight loss and (b) derivative weight loss graphs of EEGs synthesized in single salt electrolytes and (c) weight loss and (d) derivative weight loss graphs of EEGs synthesized in mixed electrolytes containing $\left(\mathrm{NH}_{4}\right)_{2} \mathrm{SO}_{4}$ and $\left(\mathrm{NH}_{4}\right)_{2} \mathrm{HPO}_{4}$ in the ratios of 50-50, 70-30, and 90-10.

The EEG exfoliated in $\mathrm{NH}_{4} \mathrm{NO}_{3}$ displayed the maximum weight $\%$ loss in stage (ii), indicating a larger amount of oxygen functional groups, and further confirming the findings from the XPS. In stage (iii), a significant difference is observed for the EEG prepared using $\left(\mathrm{NH}_{4}\right)_{2} \mathrm{HPO}_{4}$. The temperature at $50 \%$ mass loss for EEGs prepared in $\mathrm{NH}_{4} \mathrm{NO}_{3}, \mathrm{Na}_{2} \mathrm{SO}_{4}$, $\left(\mathrm{NH}_{4}\right)_{2} \mathrm{SO}_{4}$ and $\left(\mathrm{NH}_{4}\right)_{2} \mathrm{HPO}_{4}$ electrolytes were $518^{\circ} \mathrm{C}, 675^{\circ} \mathrm{C}, 695^{\circ} \mathrm{C}$ and $873^{\circ} \mathrm{C}$, respectively. This clearly shows that EEG-(NH$)_{2} \mathrm{HPO}_{4}$ has a high-temperature stability compared to the EEGs synthesized in other electrolytes. Previous studies have indicated that P-doping and phosphorous 
containing functional groups, namely $\mathrm{C}-\mathrm{PO}_{3}, \mathrm{C}_{2} \mathrm{PO}_{2}, \mathrm{C}-\mathrm{O}-\mathrm{PO}_{3},(\mathrm{CO})_{3} \mathrm{PO}_{2}, \mathrm{C}-\mathrm{O}-\mathrm{PO}(\mathrm{OH})_{2}$, and $(\mathrm{CO})_{2} \mathrm{PO}$, can enhance high-temperature stability of carbon materials $[27,52,55,56]$. The thermal stability of phosphorus functionalized carbons can be maintained up to temperatures of around $800^{\circ} \mathrm{C}$, as above this temperature the phosphorus functional groups were unbound from the $\{101\}$ faces and attached to $\{112\}$ faces $[55,56]$. This makes the surface more prone to oxidation.

A phosphorus modified graphene was prepared by Xiaowei $\mathrm{Mu}$ et al. which exhibited stability in air at temperatures of up to $>800^{\circ} \mathrm{C}$ [61], similar to that obtained in the present study. It thus seems likely that the high-temperature stability obtained in the present study for the EEG prepred in $\left(\mathrm{NH}_{4}\right)_{2} \mathrm{HPO}_{4}$ electrolytes was due to the same poisoning mechanism of the active site by P-functional groups at the surface of the graphene, as described by Xiaowei et al. [61]. Similar behaviour, including high temperature stability in air at temperaures of $>800^{\circ} \mathrm{C}$, has also been observed by Xinhu Wu et al. [62] who synthesized P-graphene by ball mixing with commercial red phosphorous. The high-temperature stability was attributed to the formation of $\mathrm{P}-\mathrm{O}-\mathrm{C}$ bonds between red $\mathrm{P}$ and graphene [62].

A more detailed mediated mechanism was suggested by Berenguer et al. to elaborate the oxidation of phosphorus coated activated carbon. The mechanism includes the influence of phosphorus functional group, with favoured oxygen acceptance, which are progressively changed from less-to more-oxidized highly stable species; and the sluggish and delayed transfer of accepted oxygen from highly stable phosphorus species to adjacent carbon sites [56].

The XPS results for the EEG-(NH$)_{2} \mathrm{HPO}_{4}$ demonstarted the formation of phosphorous containing functional groups and also phosphorous doping which can be responsible for this high -temperature stability. This phenomenon can also be ascribed to the higher graphitic carbon $\left(\mathrm{sp}^{2}\right)$ content for EEG prepared by $\left(\mathrm{NH}_{4}\right)_{2} \mathrm{HPO}_{4}$, as indicated by XPS results. The EEGs exfoliated in 
$\left(\mathrm{NH}_{4}\right)_{2} \mathrm{SO}_{4}$ showed the minimum wt\% loss in stage (ii), indicating a lower amount of oxygen functional groups, which is consitent with the findings from XPS. In stage (iii), EEG prepared using $\left(\mathrm{NH}_{4}\right)_{2} \mathrm{SO}_{4}$ showed better high-temperature stability in comparison to EEG-NH $\mathrm{N}_{4} \mathrm{NO}_{3}$, but lower than that for EEG-(NH$)_{2} \mathrm{HPO}_{4}$. This can be assigned to higher graphitic $\left(\mathrm{sp}^{2}\right)$ content of EEG-(NH$)_{2} \mathrm{SO}_{4}$ compared to EEG-NH $\mathrm{NHO}_{3}$, but the lack of the phosphorus fucntional groups on its surface led to lower high-temperature stability compared to EEG-(NH4) ${ }_{2} \mathrm{HPO}_{4}$.

The high-temperature stability of the prepared EEGs with mixed electrolytes is illustrated in Figure 8 (c) and (d). With electrolyte comprising a mixture of $\left(\mathrm{NH}_{4}\right)_{2} \mathrm{HPO}_{4}$ and $\left(\mathrm{NH}_{4}\right)_{2} \mathrm{SO}_{4}$, $\left(\mathrm{NH}_{4}\right)_{2} \mathrm{HPO}_{4}$ worked as the source of the P-containing functional groups and led to almost the same trend of high-temperature stability on the EEG as that obtained for the electrolyte containing $\left(\mathrm{NH}_{4}\right)_{2} \mathrm{HPO}_{4}$ alone. However, EEGs 70-30 and 50-50 samples demonstrate a slightly higher temperature stability compared to EEG-(NH$)_{2} \mathrm{HPO}_{4}$ alone. This can be attributted to a higher number of monolayer and bilayer graphenes in the former. On the other hand, although the EEGs synthesized from the mixtures of these two salts in the ratio of 90-10 had a high number of monolayer and bilayer, but much lower amount of P-containing functional groups made its hightemperature stability to be lower than the EEG from $\left(\mathrm{NH}_{4}\right)_{2} \mathrm{HPO}_{4}$ alone. It is notable that using a mixed electrolyte with $70 \%\left(\mathrm{NH}_{4}\right)_{2} \mathrm{SO}_{4}$ provided a higher proportion of single layer EEG depicting a more efficient exfoliation (as seen in Figure 7) and also induced higher high-temperature stability as observed in the TGA analysis. The EEG exfoliated using $90 \%\left(\mathrm{NH}_{4}\right)_{2} \mathrm{SO}_{4}$ also resulted in a large number of single layer graphene particles, while the EEG prepared using $50 \%\left(\mathrm{NH}_{4}\right)_{2} \mathrm{SO}_{4}$ had similar characteristics to EEG-(NH$)_{2} \mathrm{HPO}_{4}$.

In order to further study the mechanim of exfoliation in a time scale, the cross section (Figure S7, close to the surface of electrode and Figure S8, center of the electrode) of the graphite 
anode was examined using SEM after 15, 30 and 60 min of intercalation/exfoliation of the graphite. As observed from the presented images, intercalation and expansion of graphite happens more quickly using $\left(\mathrm{NH}_{4}\right)_{2} \mathrm{SO}_{4}$ in comparison to $\left(\mathrm{NH}_{4}\right)_{2} \mathrm{HPO}_{4}$. It is proposed that intercalation of $\mathrm{HPO}_{4}$ ions between the graphite sheet and subsequent expansion of the layers is less significant than observed in the $\left(\mathrm{NH}_{4}\right)_{2} \mathrm{SO}_{4}$ electrolyte, probably resulting in EEGs with multilayers. With a mixed electrolye, the intercalation/expansion observed is similar to that seen with $\left(\mathrm{NH}_{4}\right)_{2} \mathrm{SO}_{4}$ electrolyte, leading to more monolayer/ bilayer EEGs.

Figure 9 depicts a schematic diagram suggesting a mechanism for the addition of the $\left(\mathrm{NH}_{4}\right)_{2} \mathrm{HPO}_{4}$ to $\left(\mathrm{NH}_{4}\right)_{2} \mathrm{SO}_{4}$ leading to exfoliation of the graphite. Higginbotham et al. proposed that during the unzipping process of carbon nanotube to graphene nanoribbon, the addition of the $\mathrm{H}_{3} \mathrm{PO}_{4}$ to the $\mathrm{H}_{2} \mathrm{SO}_{4}$ solution can improve the chemoselectivity and reduce the oxidation process. Similarily, it can be concluded that the presence of the $\left(\mathrm{NH}_{4}\right)_{2} \mathrm{HPO}_{4}$ can minimize the oxidation process which happens during the electrochemical exfoliation. During the electrochemical oxidation and exfoliation processes, hydroxyl radicals can attack the $\mathrm{sp}^{2}$ carbons in the graphite structure creating two vicinal $\mathrm{OH}$ groups [63]. Therefore, the synthesized material is a partially oxidized graphene (or few layer graphene). As observed in the XPS results, the EEG exfoliated in pure $\left(\mathrm{NH}_{4}\right)_{2} \mathrm{SO}_{4}$ contains a considerable amount of carbonyl groups leading to the existence of more holes and defects in the structure of the graphene. The carbonyl groups are formed as a result of further oxidation at the surface of graphene, where hydroxyl groups at the surface break the carboncarbon bond and create diones and more irreversible defects in the structure. The addition of the $\left(\mathrm{NH}_{4}\right)_{2} \mathrm{HPO}_{4}$ salt during the exfoliation process may prevent the oxidation of hydroxyl groups (vicinal diols) into carbonyl groups (diones) by creating a cyclic structure containing phosphorous 
groups, and this is confirmed by the observation of phosphorous groups and fewer carbonyl groups in the XPS results.

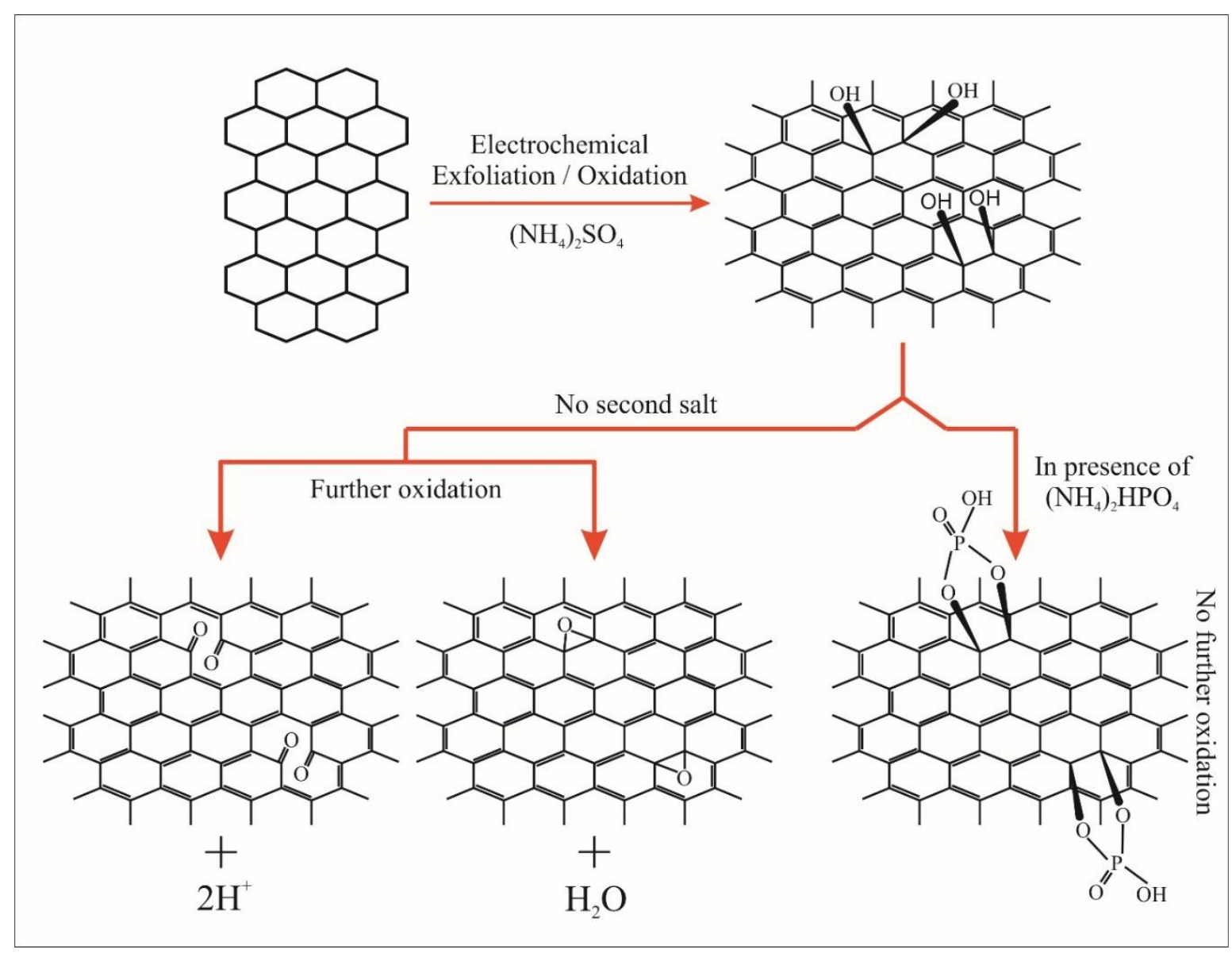

Figure 9. Suggested mechanism for the effect of $\left(\mathrm{NH}_{4}\right)_{2} \mathrm{HPO}_{4}$ on the surface chemistry of the electrochemically exfoliated graphene.

One of the important factors that affects the electrical conductivity of graphene films is degree of oxidation $[64,65]$. Graphene produced by chemical exfoliation has very low electrical conductivity and poor thermal conductivity due to aggressive oxidation resulting in covalent functionalization of oxygen-containing groups, which intensely changes the graphene structure and properties. The low conductivity of oxidized graphene is a consequence of the functionalization which disturbs the conjugated structure and localizes p-electrons leading to a 
decrease of both carrier mobility and carrier concentration. As shown in Fig 10 the electrical conductivity trend for as prepared EEGs films is: $\sigma_{\left(\mathrm{NH}_{4}\right)_{2} \mathrm{HPO}_{4}+\left(\mathrm{NH}_{4}\right)_{2} \mathrm{SO}_{4}(70: 30)}=(48.6 \pm 0.6) \times$ $10^{2} \mathrm{~S} / \mathrm{m}>\sigma_{\left(\mathrm{NH}_{4}\right)_{2} \mathrm{HPO}_{4}}=(31.1 \pm 1.1) \times 10^{2} \mathrm{~S} / \mathrm{m}>\sigma_{\left(\mathrm{NH}_{4}\right)_{2} \mathrm{HPO}_{4}+\left(\mathrm{NH}_{4}\right)_{2} \mathrm{SO}_{4}(50: 50)}=(25.7 \pm 5.7) \times$ $10^{2} \mathrm{~S} / \mathrm{m} \geq \sigma_{\left(\mathrm{NH}_{4}\right)_{2} \mathrm{HPO}_{4}+\left(\mathrm{NH}_{4}\right)_{2} \mathrm{SO}_{4}(90: 10)}=(24.3 \pm 2.7) \times 10^{2} \mathrm{~S} / \mathrm{m}>\sigma_{\left(\mathrm{NH}_{4}\right)_{2} \mathrm{SO}_{4}}=(17.6 \pm 0.1) \times$ $10^{2} \mathrm{~S} / \mathrm{m}>\sigma_{\mathrm{NH}_{4} \mathrm{NO}_{3}}=(0.9 \pm 0.1) \times 10^{2}$.

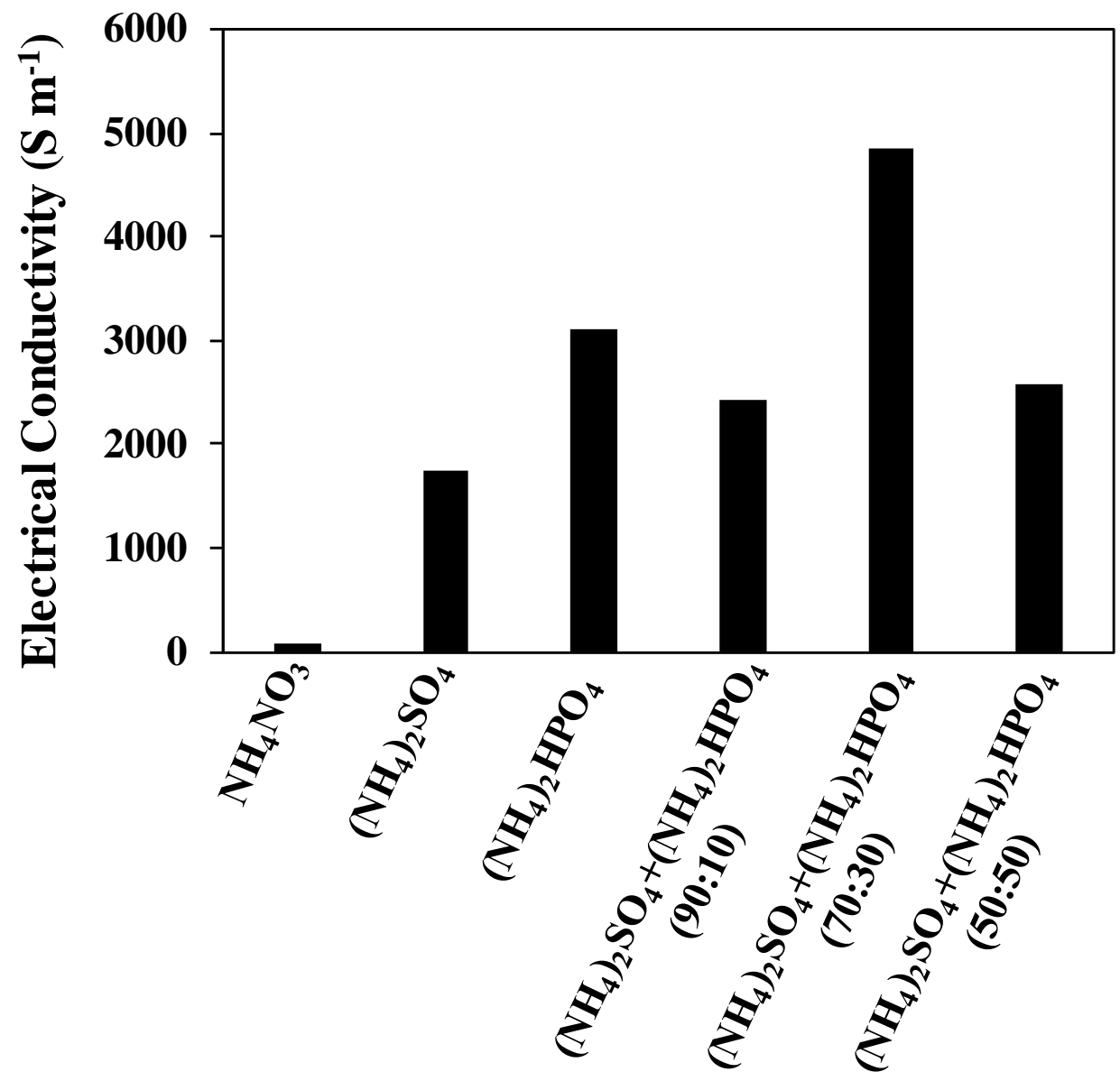

Figure 10. The electrical conductivity of the EEG prepared using different electrolytes.

With the exception of the EEG prepared using $\mathrm{NH}_{4} \mathrm{NO}_{3}$, the conductivities are excellent, similar to reduced graphene oxide and recently reported values of $21 \times 10^{2} \mathrm{~S} / \mathrm{m}[66]$ and $44 \times 10^{2}$ S/m [67] for as prepared EEGs. The addition of the $\left(\mathrm{NH}_{4}\right)_{2} \mathrm{HPO}_{4}$ to the electrolyte prevents the 
excessive oxidation of the graphene, lowering the degree of oxidation, consequently increasing the conductivity. The higher electrical conductiivty of the $70-30$ mixed $\left(\mathrm{NH}_{4}\right)_{2} \mathrm{SO}_{4} /\left(\mathrm{NH}_{4}\right)_{2} \mathrm{HPO}_{4}$ electrolyte EEG confirms that this material has a the lowest level of oxidation. The conductivities of the EEG may be increased by thermal annealing or chemical reduction, and this will be the subject of future studies.

\section{Conclusions}

Graphene sheet with lower defect and high-temperature stability were synthesized using a facile and new electrochemical exfoliation approach and the impact of the synthesis conditions on the physical/chemical structure of EEGs was investigated. The results show that the samples prepared with phosphate and sulfate anions had a lower amount of functional groups compared to the other salts tested.

The graphene exfoliated in ammonium phosphate electrolyte was found to have an unusually hightemperature stability in air, with very little mass loss up to $750{ }^{\circ} \mathrm{C}$, associated with phosphorus functional groups at the surface and the periphery of the graphene. This is highly unusual for a high surface area carbon material, as they are typically unstable at temperatures of 400 to $500{ }^{\circ} \mathrm{C}$. Further studies is needed to determine whether the observed material properties and characteristics are changed following exposure to the electrochemically oxidative application such as the catalyst support for the fuel cells. This resistance to oxidation could indicate that this material will offer reduced corrosion in electrochemical applications. Therfore, it could also open up other possibilities to be adopted as an electrode and current supply in high-temperature electrochemical technologies. 
A mixture electrolyte contaning differnet ratio of $\left(\mathrm{NH}_{4}\right)_{2} \mathrm{HPO}_{4}$ and $\left(\mathrm{NH}_{4}\right)_{2} \mathrm{SO}_{4}$ was also employed for the exfoliation. The EEGs exfoliated in $\left(\mathrm{NH}_{4}\right)_{2} \mathrm{HPO}_{4}$ or the mixed electrolyte exhibited a higher degree of crystallinity and fewer defects, due to the phosphorous functional groups binding with diols during the exfoliation process and avoiding further oxidation of the surface. The EEG prepared using $\left(\mathrm{NH}_{4}\right)_{2} \mathrm{HPO}_{4}$ containing electrolytes had fewer defects than the other EEGs. This suggests that the presence of $\left(\mathrm{NH}_{4}\right)_{2} \mathrm{HPO}_{4}$ in the electrolyte leads to less damage of the basal plane of the exfoliated graphene than other electrolytes. The EEGs prepared using the mixed electrolyte demonstrated high temperature stability similar to EEG prepared in pure $\left(\mathrm{NH}_{4}\right)_{2} \mathrm{HPO}_{4}$, while possessing the highest number of the monolayer $(\sim 50 \%)$ and bilayer $(\sim 40 \%)$ sheets. We postulate that this improved procedure did not lead to digestion of the thinner sheet resulting in better exfoliation. This facile method has signficant potential for scale up in the production of few layer graphene materials, since it uses relatively low toxicity dilute salts, and operates under ambient

pressure and temperature. Recognizing the distinct dependence of the synthesized graphene properties on the electrolyte composition provides a starting point for tailoring these properties to applications of interest.

\section{Acknowledgments}

This research has received financial support from the Natural Sciences and Engineering Research Council of Canada (NSERC 435634-2013) and the Canada Foundation for Innovation (CFI 32613). The UK authors would like to acknowledge the EPSRC funding (EPSRC Grant No. EP/P009050/1) and (EPSRC Grant No EP/N013670/1). We are grateful to Ms. Tavous Jalilian for designing and drawing the schematics. 


\section{References}

[1] X. Duan, C. Zhao, W. Liu, X. Zhao, L. Chang, Fabrication of a novel PbO2 electrode with a graphene nanosheet interlayer for electrochemical oxidation of 2-chlorophenol, Electrochim. Acta. 240 (2017) 424-436. doi:10.1016/J.ELECTACTA.2017.04.114.

[2] M.A. Betiha, A.M. Rabie, H.S. Ahmed, A.A. Abdelrahman, M.F. El-Shahat, Oxidative desulfurization using graphene and its composites for fuel containing thiophene and its derivatives: An update review, Egypt. J. Pet. (2017). doi:10.1016/J.EJPE.2017.10.006.

[3] Y. Cheng, J. Lin, K. Xu, H. Wang, X. Yao, Y. Pei, S. Yan, M. Qiao, B. Zong, FischerTropsch Synthesis to Lower Olefins over Potassium-Promoted Reduced Graphene Oxide Supported Iron Catalysts, ACS Catal. 6 (2016) 389-399. doi:10.1021/acscatal.5b02024.

[4] H. Zhao, Q. Zhu, Y. Gao, P. Zhai, D. Ma, Iron oxide nanoparticles supported on pyrolytic graphene oxide as model catalysts for Fischer Tropsch synthesis, Appl. Catal. A Gen. 456 (2013) 233-239. doi:10.1016/J.APCATA.2013.03.006.

[5] Y. Gao, Y. Li, L. Zhang, H. Huang, J. Hu, S.M. Shah, X. Su, Adsorption and removal of tetracycline antibiotics from aqueous solution by graphene oxide, J. Colloid Interface Sci. 368 (2012) 540-546. doi:10.1016/J.JCIS.2011.11.015.

[6] V. Chandra, K.S. Kim, Highly selective adsorption of $\mathrm{Hg} 2+$ by a polypyrrole-reduced graphene oxide composite, Chem. Commun. $47 \quad$ (2011) 3942-3944. doi:10.1039/C1CC00005E.

[7] R. Imran Jafri, N. Rajalakshmi, S. Ramaprabhu, Nitrogen doped graphene nanoplatelets as catalyst support for oxygen reduction reaction in proton exchange membrane fuel cell, J. Mater. Chem. 20 (2010) 7114-7117. doi:10.1039/C0JM00467G.

[8] S. Yuyan, W. Jun, W. Hong, L. Jun, A.I. A., L. Yuehe, Graphene Based Electrochemical 
Sensors and Biosensors: A Review, Electroanalysis. 22 (n.d.) 1027-1036. doi:10.1002/elan.200900571.

[9] Z.-S. Wu, W. Ren, L. Wen, L. Gao, J. Zhao, Z. Chen, G. Zhou, F. Li, H.-M. Cheng, Graphene Anchored with Co3O4 Nanoparticles as Anode of Lithium Ion Batteries with Enhanced Reversible Capacity and Cyclic Performance, ACS Nano. 4 (2010) 3187-3194. doi:10.1021/nn100740x.

[10] K.S. Novoselov, A.K. Geim, S. V Morozov, D. Jiang, Y. Zhang, S. V Dubonos, I. V Grigorieva, A.A. Firsov, Electric Field Effect in Atomically Thin Carbon Films, Science (80-. ). 306 (2004) 666-669. http://science.sciencemag.org/content/306/5696/666.abstract.

[11] A. Ambrosi, M. Pumera, The CVD graphene transfer procedure introduces metallic impurities which alter the graphene electrochemical properties, Nanoscale. 6 (2014) 472476. doi:10.1039/C3NR05230C.

[12] S. Pei, H.-M. Cheng, The reduction of graphene oxide, Carbon N. Y. 50 (2012) 3210-3228. doi:10.1016/J.CARBON.2011.11.010.

[13] R. Gondosiswanto, X. Lu, C. Zhao, Preparation of Metal-Free Nitrogen-Doped Graphene Via Direct Electrochemical Exfoliation of Graphite in Ammonium Nitrate, Aust. J. Chem. 68 (2015) 830-835. https://doi.org/10.1071/CH14447.

[14] J. Lu, J. Yang, J. Wang, A. Lim, S. Wang, K.P. Loh, One-Pot Synthesis of Fluorescent Carbon Nanoribbons, Nanoparticles, and Graphene by the Exfoliation of Graphite in Ionic Liquids, ACS Nano. 3 (2009) 2367-2375. doi:10.1021/nn900546b.

[15] X. Lu, C. Zhao, Controlled electrochemical intercalation $\{$,$\} exfoliation and in situ nitrogen$ doping of graphite in nitrate-based protic ionic liquids, Phys. Chem. Chem. Phys. 15 (2013) 20005-20009. doi:10.1039/C3CP53917B. 
[16] J. Liu, C.K. Poh, D. Zhan, L. Lai, S.H. Lim, L. Wang, X. Liu, N. Gopal Sahoo, C. Li, Z. Shen, J. Lin, Improved synthesis of graphene flakes from the multiple electrochemical exfoliation of graphite rod, Nano Energy. 2 (2013) 377-386. doi:10.1016/J.NANOEN.2012.11.003.

[17] J. Liu, H. Yang, S.G. Zhen, C.K. Poh, A. Chaurasia, J. Luo, X. Wu, E.K.L. Yeow, N.G. Sahoo, J. Lin, Z. Shen, A green approach to the synthesis of high-quality graphene oxide flakes via electrochemical exfoliation of pencil core, RSC Adv. 3 (2013) 11745-11750. doi:10.1039/C3RA41366G.

[18] K. Chen, D. Xue, Preparation of colloidal graphene in quantity by electrochemical exfoliation, J. Colloid Interface Sci. 436 (2014) 41-46. doi:10.1016/J.JCIS.2014.08.057.

[19] N. Parveen, M.O. Ansari, M.H. Cho, Simple route for gram synthesis of less defective few layered graphene and its electrochemical performance, RSC Adv. 5 (2015) 44920-44927. doi:10.1039/C5RA06404J.

[20] K. Parvez, Z.-S. Wu, R. Li, X. Liu, R. Graf, X. Feng, K. Müllen, Exfoliation of Graphite into Graphene in Aqueous Solutions of Inorganic Salts, J. Am. Chem. Soc. 136 (2014) 6083-6091. doi:10.1021/ja5017156.

[21] A. Kozawa, K. Fujita, A. Sato, D. Brodd, Recent new additives for electric vehicle leadacid batteries for extending the cycle life and capacity, in: Twelfth Annu. Batter. Conf. Appl. Adv., IEEE, 1997: pp. 277-282.

[22] W. Zhang, Y. Zeng, N. Xiao, H.H. Hng, Q. Yan, One-step electrochemical preparation of graphene-based heterostructures for Li storage, J. Mater. Chem. 22 (2012) 8455-8461.

[23] F. Lou, M.E.M. Buan, N. Muthuswamy, J.C. Walmsley, M. Rønning, D. Chen, One-step electrochemical synthesis of tunable nitrogen-doped graphene, J. Mater. Chem. A. 4 (2016) 
$1233-1243$.

[24] J. Cao, P. He, M.A. Mohammed, X. Zhao, R.J. Young, B. Derby, I.A. Kinloch, R.A.W. Dryfe, Two-Step Electrochemical Intercalation and Oxidation of Graphite for the Mass Production of Graphene Oxide, J. Am. Chem. Soc. 139 (2017) 17446-17456. doi:10.1021/jacs.7b08515.

[25] Z. Morávková, M. Trchová, E. Tomšík, J. Čechvala, J. Stejskal, Enhanced thermal stability of multi-walled carbon nanotubes after coating with polyaniline salt, Polym. Degrad. Stab. 97 (2012) 1405-1414. doi:https://doi.org/10.1016/j.polymdegradstab.2012.05.019.

[26] S. Labruquère, R. Pailler, R. Naslain, B. Desbat, Oxidation Inhibition of Carbon Fibre Preforms and C/C Composites by H3PO4, J. Eur. Ceram. Soc. 18 (1998) 1953-1960. doi:10.1016/S0955-2219(98)00135-6.

[27] J.M. Rosas, R. Ruiz-Rosas, J. Rodríguez-Mirasol, T. Cordero, Kinetic study of the oxidation resistance of phosphorus-containing activated carbons, Carbon N. Y. 50 (2012) 1523-1537. doi:10.1016/J.CARBON.2011.11.030.

[28] X. Wu, L.R. Radovic, Inhibition of catalytic oxidation of carbon/carbon composites by $\begin{array}{llllll}\text { phosphorus, } & \text { Carbon } & \text { N. } & \text { Y. } & 44 & \text { (2006) }\end{array}$ doi:https://doi.org/10.1016/j.carbon.2005.06.038.

[29] S.A. Suvorov, E. V Chaikun, S.L. Korobkin, G.S. Sokolova, Protective mechanism of phosphorus-containing coatings, Refractories. $29 \quad$ (1988) 544-547. doi:10.1007/BF01287784.

[30] W. Lu, D.D.L. Chung, Oxidation protection of carbon materials by acid phosphate impregnation, Carbon N. Y. 40 (2002) 1249-1254. doi:10.1016/S0008-6223(01)00297-4.

[31] J.M. Rosas, J. Bedia, J. Rodríguez-Mirasol, T. Cordero, HEMP-derived activated carbon 
fibers by chemical activation with phosphoric acid, Fuel. 88 (2009) 19-26. doi:10.1016/J.FUEL.2008.08.004.

[32] Y. Wang, S. Zuo, J. Yang, S.-H. Yoon, Evolution of Phosphorus-Containing Groups on Activated Carbons during Heat Treatment, Langmuir. 33 (2017) 3112-3122. doi:10.1021/acs.langmuir.7b00095.

[33] D.W. McKee, C.L. Spiro, E.J. Lamby, The effects of boron additives on the oxidation behavior of carbons, Carbon N. Y. 22 (1984) 507-511. doi:10.1016/0008-6223(84)900836.

[34] S.G. Oh, N.M. Rodriguez, In situ electron microscopy studies of the inhibition of graphite oxidation by phosphorus, J. Mater. Res. 8 (1993) 2879-2888. doi:10.1557/JMR.1993.2879.

[35] D. Nečas, P. Klapetek, Gwyddion: an open-source software for SPM data analysis, Open Phys. 10 (2012) 181. doi:10.2478/s11534-011-0096-2.

[36] S. Yang, A.G. Ricciardulli, S. Liu, R. Dong, M.R. Lohe, A. Becker, M.A. Squillaci, P. Samorì, K. Müllen, X. Feng, Ultrafast Delamination of Graphite into High-Quality Graphene Using Alternating Currents, Angew. Chemie Int. Ed. 56 (2017) 6669-6675. doi:10.1002/anie.201702076.

[37] J.C. Meyer, A.K. Geim, M.I. Katsnelson, K.S. Novoselov, D. Obergfell, S. Roth, C. Girit, A. Zettl, On the roughness of single-and bi-layer graphene membranes, Solid State Commun. 143 (2007) 101-109.

[38] J. Feng, F. Pu, Z. Li, X. Li, X. Hu, J. Bai, Interfacial interactions and synergistic effect of CoNi nanocrystals and nitrogen-doped graphene in a composite microwave absorber, Carbon N. Y. 104 (2016) 214-225. doi:https://doi.org/10.1016/j.carbon.2016.04.006.

[39] S. Stankovich, D.A. Dikin, R.D. Piner, K.A. Kohlhaas, A. Kleinhammes, Y. Jia, Y. Wu, 
S.T. Nguyen, R.S. Ruoff, Synthesis of graphene-based nanosheets via chemical reduction of exfoliated graphite oxide, Carbon N. Y. 45 (2007) 1558-1565. doi:10.1016/j.carbon.2007.02.034.

[40] D.C. Marcano, D. V Kosynkin, J.M. Berlin, A. Sinitskii, Z. Sun, A. Slesarev, L.B. Alemany, W. Lu, J.M. Tour, Improved Synthesis of Graphene Oxide, ACS Nano. 4 (2010) 48064814. doi:10.1021/nn1006368.

[41] A.L. Higginbotham, D. V Kosynkin, A. Sinitskii, Z. Sun, J.M. Tour, Lower-Defect Graphene Oxide Nanoribbons from Multiwalled Carbon Nanotubes, ACS Nano. 4 (2010) 2059-2069. doi:10.1021/nn100118m.

[42] I. Khrapach, F. Withers, T.H. Bointon, D.K. Polyushkin, W.L. Barnes, S. Russo, M.F. Craciun, Novel Highly Conductive and Transparent Graphene-Based Conductors, Adv. Mater. 24 (2012) 2844-2849. doi:10.1002/adma.201200489.

[43] X. Qi, J. Qu, H.-B. Zhang, D. Yang, Y. Yu, C. Chi, Z.-Z. Yu, FeCl3 intercalated few-layer graphene for high lithium-ion storage performance, J. Mater. Chem. A. 3 (2015) $15498-$ 15504. doi:10.1039/C5TA03087K.

[44] Y. Yang, W. Shi, R. Zhang, C. Luan, Q. Zeng, C. Wang, S. Li, Z. Huang, H. Liao, X. Ji, Electrochemical Exfoliation of Graphite into Nitrogen-doped Graphene in Glycine Solution and its Energy Storage Properties, Electrochim. Acta. 204 (2016) 100-107. doi:https://doi.org/10.1016/j.electacta.2016.04.063.

[45] D. Yang, A. Velamakanni, G. Bozoklu, S. Park, M. Stoller, R.D. Piner, S. Stankovich, I. Jung, D.A. Field, C.A. Ventrice, R.S. Ruoff, Chemical analysis of graphene oxide films after heat and chemical treatments by X-ray photoelectron and Micro-Raman spectroscopy, Carbon N. Y. 47 (2009) 145-152. doi:https://doi.org/10.1016/j.carbon.2008.09.045. 
[46] S. Umrao, T.K. Gupta, S. Kumar, V.K. Singh, M.K. Sultania, J.H. Jung, I.-K. Oh, A. Srivastava, Microwave-Assisted Synthesis of Boron and Nitrogen co-doped Reduced Graphene Oxide for the Protection of Electromagnetic Radiation in Ku-Band, ACS Appl. Mater. Interfaces. 7 (2015) 19831-19842. doi:10.1021/acsami.5b05890.

[47] Z. Li, X. Li, Y. Zong, G. Tan, Y. Sun, Y. Lan, M. He, Z. Ren, X. Zheng, Solvothermal synthesis of nitrogen-doped graphene decorated by superparamagnetic $\mathrm{Fe} 3 \mathrm{O} 4$ nanoparticles and their applications as enhanced synergistic microwave absorbers, Carbon N. Y. 115 (2017) 493-502. doi:https://doi.org/10.1016/j.carbon.2017.01.036.

[48] M. Klingele, C. Pham, K.R. Vuyyuru, B. Britton, S. Holdcroft, A. Fischer, S. Thiele, Sulfur doped reduced graphene oxide as metal-free catalyst for the oxygen reduction reaction in anion and proton exchange fuel cells, Electrochem. Commun. 77 (2017) 71-75. doi:https://doi.org/10.1016/j.elecom.2017.02.015.

[49] S. Yang, L. Zhi, K. Tang, X. Feng, J. Maier, K. Müllen, Efficient Synthesis of Heteroatom ( $\mathrm{N}$ or S)-Doped Graphene Based on Ultrathin Graphene Oxide-Porous Silica Sheets for Oxygen Reduction Reactions, Adv. Funct. Mater. 22 (2012) 3634-3640. doi:10.1002/adfm.201200186.

[50] B. Quan, S.-H. Yu, D.Y. Chung, A. Jin, J.H. Park, Y.-E. Sung, Y. Piao, Single Source Precursor-based Solvothermal Synthesis of Heteroatom-doped Graphene and Its Energy Storage and Conversion Applications, Sci. Rep. $4 \quad$ (2014) 5639. http://dx.doi.org/10.1038/srep05639.

[51] X. Qiao, S. Liao, C. You, R. Chen, X. Qiao, S. Liao, C. You, R. Chen, Phosphorus and Nitrogen Dual Doped and Simultaneously Reduced Graphene Oxide with High Surface Area as Efficient Metal-Free Electrocatalyst for Oxygen Reduction, Catalysts. 5 (2015) 
981-991. doi:10.3390/catal5020981.

[52] B. Yuan, W. Xing, Y. Hu, X. Mu, J. Wang, Q. Tai, G. Li, L. Liu, K.M. Liew, Y. Hu, Boron/phosphorus doping for retarding the oxidation of reduced graphene oxide, Carbon N. Y. 101 (2016) 152-158. doi:10.1016/J.CARBON.2016.01.080.

[53] M.A. Patel, F. Luo, K. Savaram, P. Kucheryavy, Q. Xie, C. Flach, R. Mendelsohn, E. Garfunkel, J. V. Lockard, H. He, P and S dual-doped graphitic porous carbon for aerobic oxidation reactions: Enhanced catalytic activity and catalytic sites, Carbon N. Y. 114 (2017) 383-392. doi:10.1016/J.CARBON.2016.11.064.

[54] M. Shumba, T. Nyokong, Development of nanocomposites of phosphorus-nitrogen codoped graphene oxide nanosheets and nanosized cobalt phthalocyanines for electrocatalysis, Electrochim. Acta. $213 \quad$ (2016) 529-539. doi:10.1016/J.ELECTACTA.2016.07.079.

[55] M.J. Valero-Romero, F.J. García-Mateos, J. Rodríguez-Mirasol, T. Cordero, Role of surface phosphorus complexes on the oxidation of porous carbons, Fuel Process. Technol. 157 (2017) 116-126. doi:10.1016/J.FUPROC.2016.11.014.

[56] R. Berenguer, R. Ruiz-Rosas, A. Gallardo, D. Cazorla-Amorós, E. Morallón, H. Nishihara, T. Kyotani, J. Rodríguez-Mirasol, T. Cordero, Enhanced electro-oxidation resistance of carbon electrodes induced by phosphorus surface groups, Carbon N. Y. 95 (2015) 681-689. doi:https://doi.org/10.1016/j.carbon.2015.08.101.

[57] M.A. Patel, F. Luo, M.R. Khoshi, E. Rabie, Q. Zhang, C.R. Flach, R. Mendelsohn, E. Garfunkel, M. Szostak, H. He, P-Doped Porous Carbon as Metal Free Catalysts for Selective Aerobic Oxidation with an Unexpected Mechanism, ACS Nano. 10 (2016) 23052315. doi:10.1021/acsnano.5b07054. 
[58] K. Parvez, R. Li, S.R. Puniredd, Y. Hernandez, F. Hinkel, S. Wang, X. Feng, K. Müllen, Electrochemically exfoliated graphene as solution-processable, highly conductive electrodes for organic electronics, ACS Nano. 7 (2013) 3598-3606.

[59] Z.-J. Fan, W. Kai, J. Yan, T. Wei, L.-J. Zhi, J. Feng, Y. Ren, L.-P. Song, F. Wei, Facile Synthesis of Graphene Nanosheets via Fe Reduction of Exfoliated Graphite Oxide, ACS Nano. 5 (2011) 191-198. doi:10.1021/nn102339t.

[60] Z. Fan, K. Wang, T. Wei, J. Yan, L. Song, B. Shao, An environmentally friendly and efficient route for the reduction of graphene oxide by aluminum powder, Carbon N. Y. 48 (2010) 1686-1689. doi:https://doi.org/10.1016/j.carbon.2009.12.063.

[61] X. Mu, B. Yuan, X. Feng, S. Qiu, L. Song, Y. Hu, The effect of doped heteroatoms (nitrogen, boron, phosphorus) on inhibition thermal oxidation of reduced graphene oxide, RSC Adv. 6 (2016) 105021-105029.

[62] X. Wu, K. Gong, G. Zhao, W. Lou, X. Wang, W. Liu, Mechanical synthesis of chemically bonded phosphorus-graphene hybrid as high-temperature lubricating oil additive, RSC Adv. 8 (2018) 4595-4603.

[63] P. Yu, S.E. Lowe, G.P. Simon, Y.L. Zhong, Electrochemical exfoliation of graphite and production of functional graphene, Curr. Opin. Colloid Interface Sci. 20 (2015) 329-338. doi:https://doi.org/10.1016/j.cocis.2015.10.007.

[64] S. Pei, H.-M. Cheng, The reduction of graphene oxide, Carbon N. Y. 50 (2012) 3210-3228.

[65] Y.-F. Hung, C. Cheng, C.-K. Huang, C.-R. Yang, A Facile Method for Batch Preparation of Electrochemically Reduced Graphene Oxide, Nanomaterials. 9 (2019) 376.

[66] T.C. Achee, W. Sun, J.T. Hope, S.G. Quitzau, C.B. Sweeney, S.A. Shah, T. Habib, M.J. Green, High-yield scalable graphene nanosheet production from compressed graphite using 
electrochemical exfoliation. Scir Reports, 8 (2019) 14525.

[67] S.E. Lowe, G. Shi, Y. Zhang, J. Qin, L. Jiang, S. Jiang, M. Al-Mamun, P. Liu, Y.L. Zhong, H. Zhao, The role of electrolyte acid concentration in the electrochemical exfoliationof graphite: Mechanism and synthesis of electrochemical graphene oxide. Nano Materials Science 1 (2019) 215-223. 